\title{
Numerical Modeling and Parametric Study of a Dual Purpose Underground Thermal Battery
}

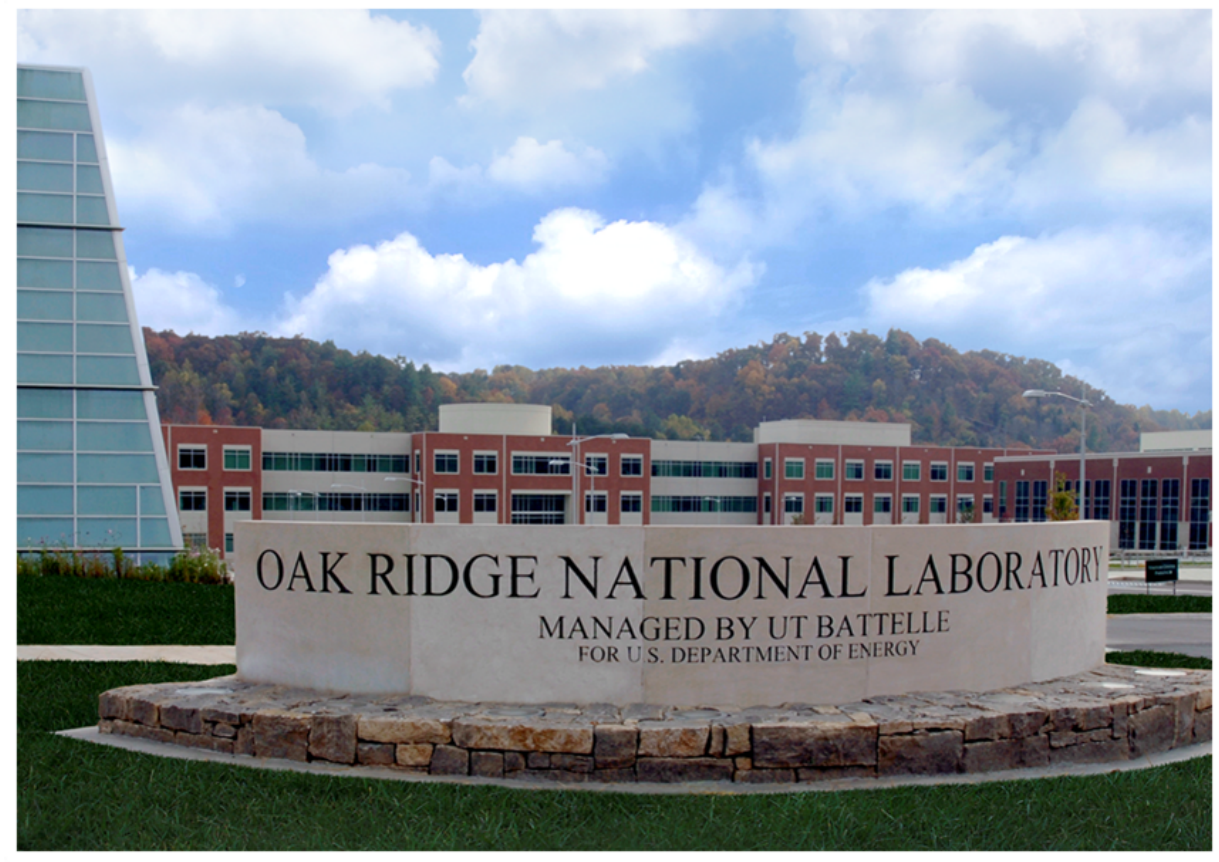

Liang Shi Xiaobing Liu Ming Qu Mingkan Zhang Lingshi Wang

October 2020 


\section{DOCUMENT AVAILABILITY}

Reports produced after January 1, 1996, are generally available free via US Department of Energy (DOE) SciTech Connect.

Website www.osti.gov

Reports produced before January 1, 1996, may be purchased by members of the public from the following source:

National Technical Information Service

5285 Port Royal Road

Springfield, VA 22161

Telephone 703-605-6000 (1-800-553-6847)

TDD 703-487-4639

Fax 703-605-6900

E-mail info@ntis.gov

Website http://classic.ntis.gov/

Reports are available to DOE employees, DOE contractors, Energy Technology Data Exchange representatives, and International Nuclear Information System representatives from the following source:

Office of Scientific and Technical Information

PO Box 62

Oak Ridge, TN 37831

Telephone 865-576-8401

Fax 865-576-5728

E-mail reports@osti.gov

Website http://www.osti.gov/contact.html

This report was prepared as an account of work sponsored by an agency of the United States Government. Neither the United States Government nor any agency thereof, nor any of their employees, makes any warranty, express or implied, or assumes any legal liability or responsibility for the accuracy, completeness, or usefulness of any information, apparatus, product, or process disclosed, or represents that its use would not infringe privately owned rights. Reference herein to any specific commercial product, process, or service by trade name, trademark, manufacturer, or otherwise, does not necessarily constitute or imply its endorsement, recommendation, or favoring by the United States Government or any agency thereof. The views and opinions of authors expressed herein do not necessarily state or reflect those of the United States Government or any agency thereof. 
Buildings and Transportation Science Division

\title{
NUMERICAL MODELING AND PARAMETRIC STUDY OF A DUAL PURPOSE UNDERGROUND THERMAL BATTERY
}

\author{
Liang Shi \\ Xiaobing Liu \\ Ming Qu \\ Mingkan Zhang \\ Lingshi Wang
}

Date Published:

October 2020

\footnotetext{
Prepared by

OAK RIDGE NATIONAL LABORATORY

Oak Ridge, TN 37831-6283

managed by

UT-BATTELLE, LLC

for the

US DEPARTMENT OF ENERGY

under contract DE-AC05-00OR22725
} 


\section{ACKNOWLEDGMENTS}

This work was sponsored by the U. S. Department of Energy's Geothermal Technologies Office under Contract No. DE-AC05-00OR22725 with UT-Battelle, LLC. The authors would like to acknowledge the support and guidance of Ms. Arlene Anderson, Technology Development Manager at the Geothermal Technologies Office of the U.S. Department of Energy. 


\section{CONTENTS}

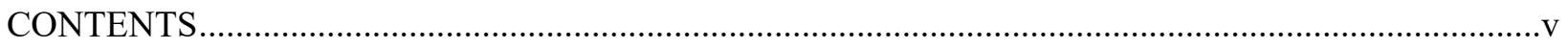

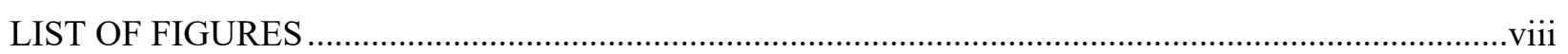

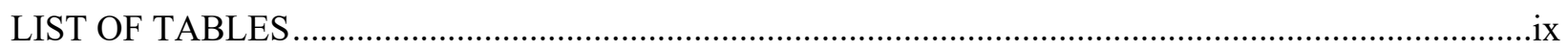

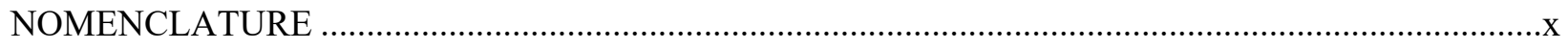

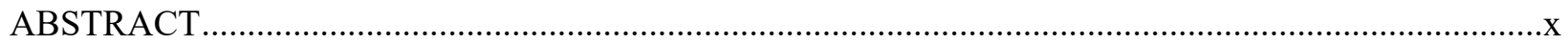

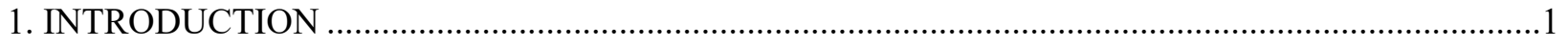

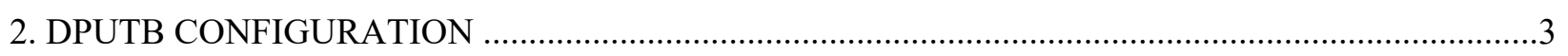

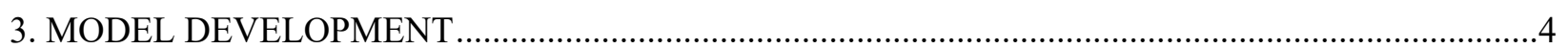

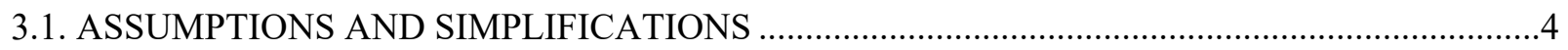

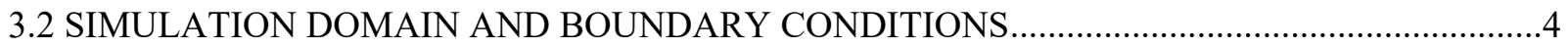

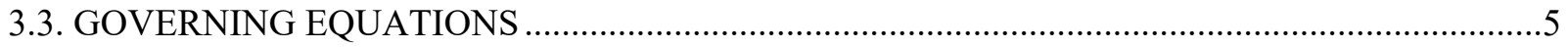

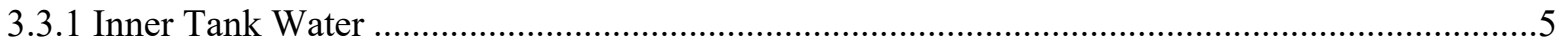

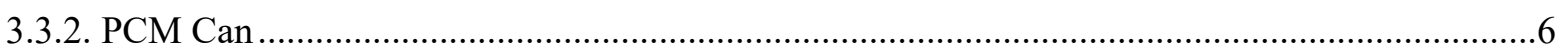

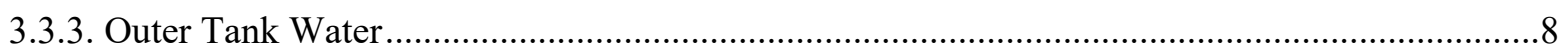

3.3.4 Heat Transfer Fluid in the Helical Heat Exchanger ....................................................................

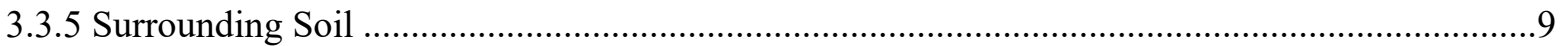

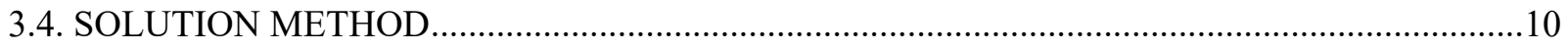

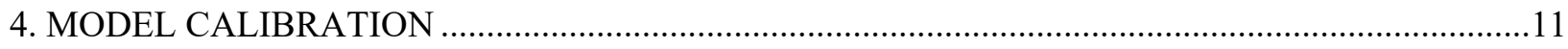

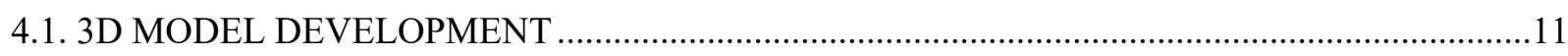

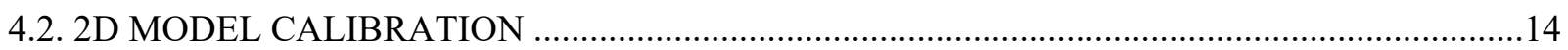

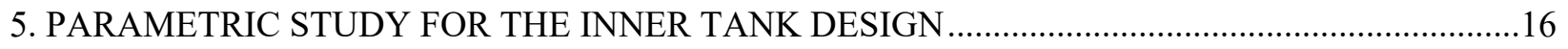

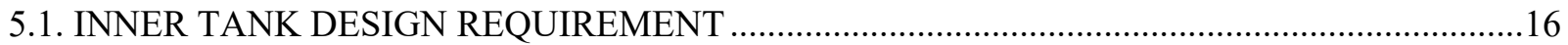

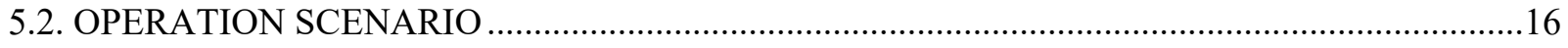

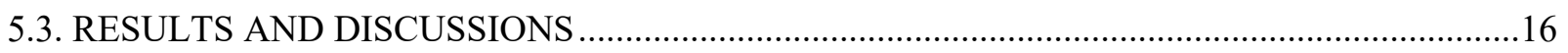

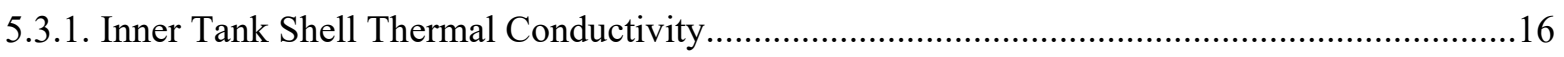

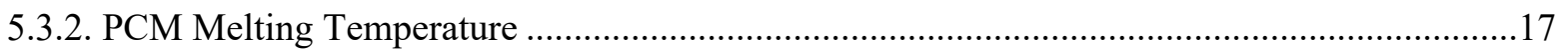

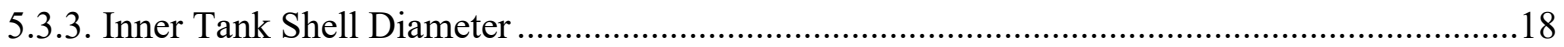

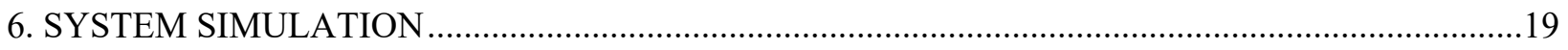

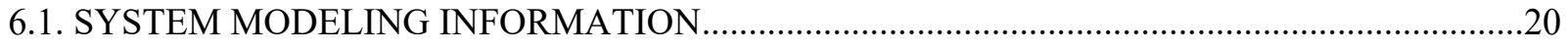

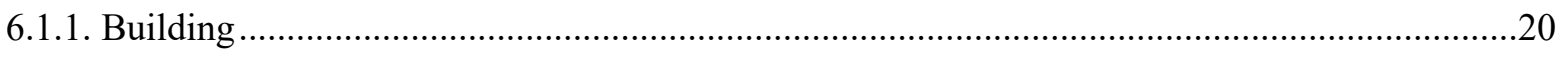

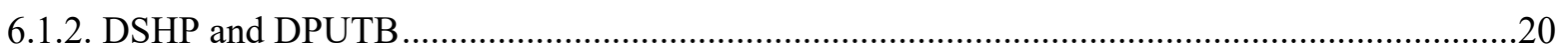

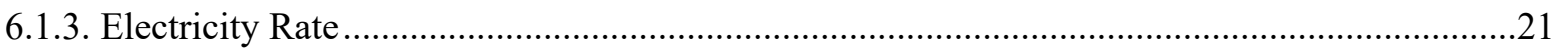

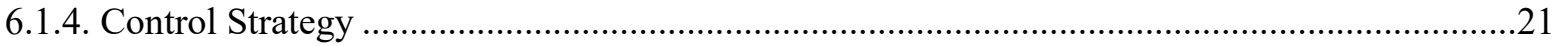

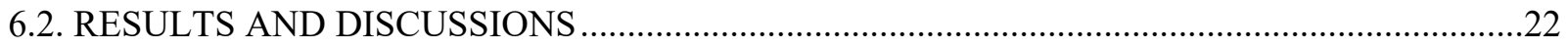

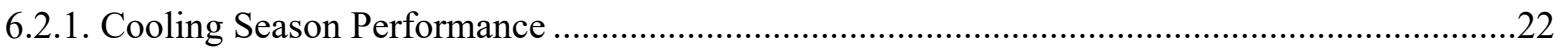


6.2.2. Heating Season Performance .25

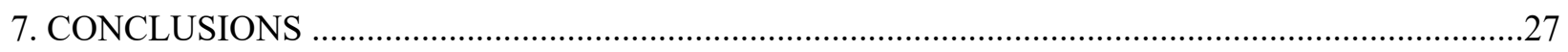

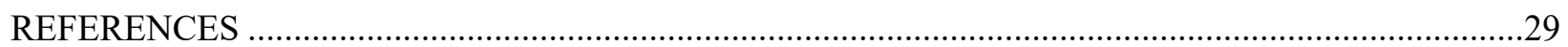




\section{LIST OF FIGURES}

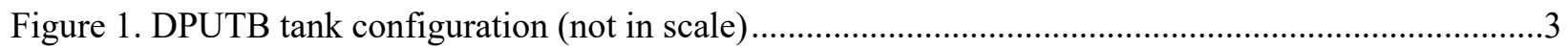

Figure 2. Diagram of simulation domain and boundary conditions .......................................................

Figure 3. The layout of PCM cans in each control volume of the inner tank ..........................................

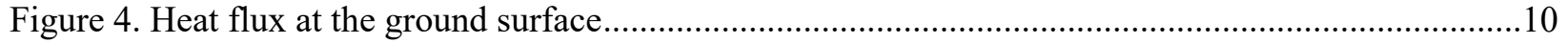

Figure 5. Flow chart of the calculation procedure of the 2D DPUTB model ...........................................11

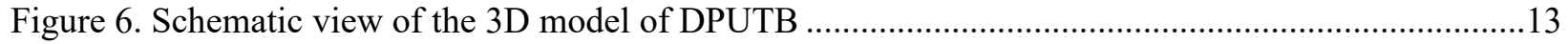

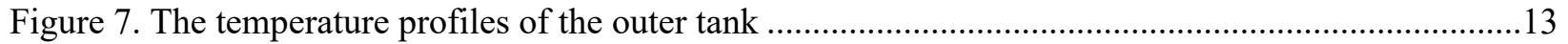

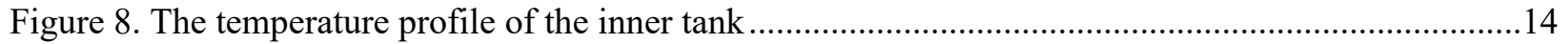

Figure 9. Comparison between the results of the 3D and the 2D models before and after

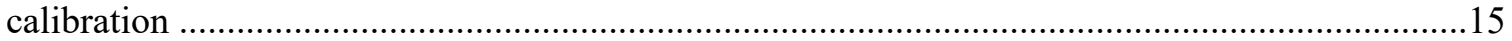

Figure 10. Parametric study result: inner tank shell thermal conductivity ….........................................17

Figure 11. Parametric study result: PCM melting temperature ............................................................18

Figure 12. Parametric study result: inner tank shell diameter..............................................................19

Figure 13. Diagram of an integrated DPUTB and DSHP system for a single-family house .....................20

Figure 14. Control strategy for (a) heating season; and (b) cooling season..............................................22

Figure 15. Featured system simulation results on July 14: (a) DPUTB and DSHP operating status; (b) building EULP resulting from the integrated DPUTB and DSHP system and the

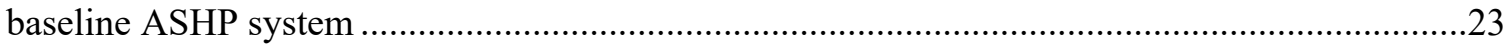

Figure 16. Inner tank outlet water temperature during the daily on-peak periods in July ........................23

Figure 17. Solid fraction of PCMs in the inner tank in July ...........................................................24

Figure 18. The outlet water temperature of the helical heat exchanger in the outer tank of the DPUTB (i.e., the source side entering water temperature of the heat pump) in July ....................24

Figure 19. Featured system simulation results on January 9: (a) DPUTB and DSHP operating status; (b) building EULP resulting from the integrated DPUTB and DSHP system and

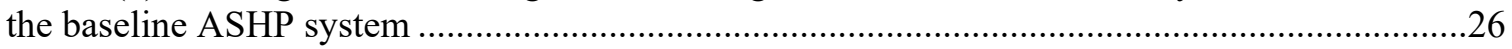

Figure 20. Inner tank outlet water temperature during the daily on-peak periods in January ....................26

Figure 21. The outlet water temperature of the helical heat exchanger in the outer tank of the DPUTB (i.e., the source side entering water temperature of the heat pump) in January..... 


\section{LIST OF TABLES}

Table 1. Dimensions of a full-size DPUTB.

Table 2. Default thermo-physical properties of PCM.........................................................................

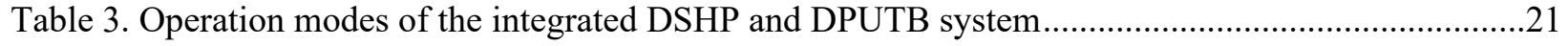

Table 4. Building electricity consumption and associated cost in July ...............................................25

Table 5. Building electricity consumption and associated cost in January..... 


\section{NOMENCLATURE}

Symbols
$A$
$c_{p}$
$D$
$f$
$\Delta H$
$\mathrm{HE}$

$h$

$k$
$L$
$\dot{\mathrm{Nu}}$
$\mathrm{Nu}$
$\mathrm{Pr}$
$q$
$\mathrm{Ra}$
$\mathrm{Re}$
$r$
$T$
$t$
$V$
$y$
$Z$

cross-section area $\left(\mathrm{m}^{2}\right)$

specific heat $(\mathrm{J} / \mathrm{kg} \mathrm{K})$

diameter $(\mathrm{m})$

factor

heat of fusion $(\mathrm{J} / \mathrm{kg})$

factor for forced convection heat transfer coefficient in the helical heat exchanger convective heat transfer coefficient $\left(\mathrm{W} / \mathrm{m}^{2}\right.$ $\mathrm{K})$ thermal conductivity $(\mathrm{W} / \mathrm{m} \mathrm{K})$

length (m)

mass flow rate $(\mathrm{kg} / \mathrm{s})$

Nusselt number

number

Prandtl number

heat transfer rate $(\mathrm{W})$

Rayleigh number

Reynolds number

radial direction or position $(\mathrm{m})$

temperature $\left({ }^{\circ} \mathrm{C}\right)$

time (s)

volume $\left(\mathrm{m}^{3}\right)$

vertical direction or position $(\mathrm{m})$

vertical direction for PCM can or position (m)

Greek symbols

$\begin{array}{ll}\lambda & \text { liquid fraction } \\ \rho & \text { density }\left(\mathrm{kg} / \mathrm{m}^{3}\right) \\ \Sigma & \text { summation }\end{array}$

Subscripts

can PCM can

coil coil of the helical heat exchanger

conv convection

evap evaporation

$\begin{array}{ll}f & \text { canopy layer } \\ g & \text { ground } \\ h & \text { hydraulic } \\ h x & \text { helical heat exchanger or the fluid in it } \\ \text { high } & \text { higher boundary } \\ l & \text { liquid phase } \\ \text { low } & \text { lower boundary } \\ m & \text { melting point } \\ \text { pcm } & \text { phase change material } \\ \text { rad } & \text { radiation } \\ \text { s } & \text { solid phase } \\ \text { sky } & \text { sky temperature related } \\ \text { solar } & \text { solar radiation } \\ \text { w1 } & \text { inner tank water } \\ w 2 & \text { outer tank water }\end{array}$

Abbreviations

$\begin{array}{ll}\text { ASHP } & \text { air source heat pump } \\ \text { AWHP } & \text { air-water heat pump } \\ \text { COP } & \text { coefficient of performance } \\ \text { DPUTB } & \text { dual-purpose underground thermal battery } \\ \text { DSHP } & \text { dual-source heat pump } \\ \text { DSM } & \text { demand-side management } \\ \text { GHE } & \text { ground heat exchanger } \\ \text { GSHP } & \text { ground source heat pump } \\ \text { HDPE } & \text { high-density polyethylene } \\ \text { PCM } & \text { phase change material } \\ \text { PVC } & \text { polyvinyl chloride } \\ \text { SBGHE } & \text { shallow bore ground heat exchanger } \\ \text { TES } & \text { thermal energy storage } \\ \text { TMY } & \text { typical meteorological year } \\ \text { TOU } & \text { time-of-use } \\ \text { UTB } & \text { underground thermal battery } \\ \text { VBGHE } & \text { vertical bore ground heat exchanger } \\ \text { WWHP } & \text { water-water heat pump }\end{array}$




\begin{abstract}
Buildings' thermal energy systems for providing space heating/cooling consume a considerable amount of electricity nationwide. Integrating thermal energy storage with buildings' thermal systems has the potential to shave the peak electric demand and to overcome the mismatch between the intermittent renewable power and the fluctuating daily demand for electricity. A novel dual-purpose underground thermal battery (DPUTB) has been developed to provide diurnal thermal energy storage in conjunction with a dual-source heat pump (DSHP)system. A two-dimensional numerical model is developed to simulate the transient performance of the DPUTB. This model has similar accuracy as a detailed three-dimensional model developed with commercial heat transfer and fluid dynamics simulation program but with 1000 times faster computational speed. A parametric study is performed to identify a design of the DPUTB that can provide $14 \mathrm{kWh}$ thermal storage capacity for each charging and discharging cycle. A system simulation has been developed to assess the performance of the designed DPUTB when it is integrated with a DSHP for conditioning a typical residential building in summer and winter. Simulation results indicate that the DPUTB can meet all the design requirements in both summer and winter with the simple rule-based control strategy and the overall integrated DPUTB and DSHP system can shift the electric load for meeting the thermal demand from the peak hours to off-peak hours during a day, which would result in considerable energy cost savings if a Time of Use electricity tariff is applicable.
\end{abstract}




\section{INTRODUCTION}

Renewable power (solar, wind, etc.) penetration grows quickly in recent years as an effort to reduce greenhouse gas emissions. However, the intermittent outputs of renewable power raise challenges to the existing electric grids. It calls for high flexibility from both supply and demand sides. Therefore, efficient energy storage is required.

According to Energy Information Administrator, buildings consume $73 \%$ of all U.S. electricity [1] and space heating and space cooling consume $22 \%$ and $14 \%$ of the total electricity in residential and commercial buildings, respectively, on an annual basis [2]. It indicates that space heating and cooling for buildings is responsible for $13 \%$ of the total electricity consumption each year in the U.S. Therefore, the building thermal systems can be utilized as distributed assets for demand-side management (DSM). Thermal energy storage (TES) allows storing thermal energy generated with overproduced renewable power, or electricity from the grid during off-peak hours, and using them to meet the thermal demands of buildings during the on-peak period. Integrating TES with an electric-driven heat pump is a promising solution to enable flexible electric demand at buildings [3]. It can provide valuable load shifting capabilities at buildings to reduce the operation cost of utility companies for meeting the demands for electricity without increasing power generation capacity [4].

Generally, there are two options for applying TES in buildings: passive TES utilizing building thermal mass (e.g., wall, roof, or floor) or active TES through thermal storage tanks. Active TES has several advantages over passive TES, including:

- TES tank can be actively controlled for both charging and discharging operation;

- Operation of a TES tank would not compromise the thermal comfort of the occupants;

- Thermal loss of TES tank is lower than building envelopes;

- TES tank is applicable in residential buildings which usually have small thermal mass, and

- TES tank could have a larger thermal storage capacity than building envelopes.

Previous studies have investigated various TES tanks for DSM. Stratified water tanks are widely used due to its availability and low cost [4-6]. Renaldi et al. [5] proposed an optimization method to minimize the total operating cost of the system. The simulation result indicated that a $6 \%$ energy cost reduction can be achieved with the proposed system compared with a conventional gas boiler system when a time-of-use electricity rate is available. Arteconi et al. [4] used TES tanks to shift electric load during 3-hour peak hours to off-peak hours. They concluded that by integrating a TES tank with a heat pump system, the load shifting can be realized without influencing the indoor thermal comfort. However, $4 \%$ more electricity was consumed compared to the baseline heat pump system (without TES). Stratified water tanks are also applied for DSM in cooling applications. Yan et al. [6] proposed an active TES using a chilled water tank in an office building in Hong Kong. The simulation results showed that the proposed system was able to reduce the capacity of the chiller by $24 \%$. However, $2.6 \%$ more electricity was consumed due to additional pumping and thermal loss from the TES tank. Besides water tanks, phase change material (PCM) tanks $[7,8]$ are also applied to heat pump systems for DSM to increase the energy storage density. Most previous studies for PCM tank integrated thermal systems are only for the heating application. Lizana et al. [7] integrated a stratified PCM tank with an air-water heat pump (AWHP) in a residential building in the United Kingdom and proposed a control strategy to minimize the electric cost by utilizing a time-of-use (TOU) electric rate tariff. The simulation results indicate a $20 \%$ electricity cost reduction, while the total electricity consumption increased by $8 \%$. Hirmiz et al. [8] studied a residential ground source heat pump (GSHP) system in Canada, which was integrated with a hybrid PCM and water tank. They found the system could shift 6 hours of peak electric demand to off-peak hours. By applying PCM, the tank volume was reduced by 3 folds compared with water tanks.

TES tanks in previous studies are installed above the ground, which not only occupies floor area but also needs heavy insulation to reduce heat loss. Besides, the cost of the TES integrated thermal system is higher than the conventional heating and cooling system due to the additional component for the TES tank. As a result, its application is limited despite its potential benefits to both the building owners and the grid operators. 
Air source heat pumps (ASHPs) are more commonly used in the United States than GSHPs due to lower cost and simpler installation. However, the coefficient of performance (COP) of ASHPs generally is lower than that of GSHPs, especially in hot or cold weather. Besides, auxiliary heating is typically required for ASHPs in heating-dominated area, it reduces the seasonal energy efficiency of ASHPs. Large scale application of ASHPs could stress electric grids in winter. For GSHPs, its application is hindered in the United States due to the high cost of installation. The ground heat exchanger (GHE), which is used for heat exchange with the surrounding ground formation, accounts for about $30 \%$ of the total installation cost of a GSHP system [9]. The most commonly used GHE in the United States is the vertical bore ground heat exchanger (VBGHE), and the expensive drilling required to create the vertical borehole is the primary factor contributing to the high cost of VBGHE installation [10].

To address the economic challenge of the VBGHE, researchers have explored several new shallow bore ground heat exchangers (SBGHE) in recent years. One example of the SBGHE is the basket heat exchanger. A basket heat exchanger consists of a helical coil wrapped around supporting rods and buried in a shallow borehole, which is $8 \mathrm{~m}$ deep and with a $0.26 \mathrm{~m}$ diameter. Field tests of the basket heat exchangers showed that the heat transfer of the basket heat exchangers is highly sensitive to the thermal conductivity of the backfill material and the surrounding soil [11]. Another kind of SBGHE is GeoColumn [12]. It utilizes a shallow tank ( $6 \mathrm{~m}$ long with $0.76 \mathrm{~m}$ diameter), filled with water and buried in the ground, to exchange heat with the surrounding soil. A heat exchanger coil transfers heat from a refrigerant to the tank. The water in the tank provides a larger heat capacity than the conventional VBGHE. However, the cost and performance of this design have not been thoroughly investigated, especially for longer terms. Also, this design requires a large amount of refrigerant to fill the heat exchanger and may create a difficulty for the lubricating oil returning to the compressor. Najib et al. [13] described a field test of a helical GHE that was installed in a vertical borehole with $0.6 \mathrm{~m}$ diameter and $6 \mathrm{~m}$ depth. The helical GHE is made with high-density polyethylene (HDPE) pipe and the borehole is backfilled with the native soil. The field test results showed that the average heat transfer rate to the ground for each SBGHE was limited (335W) due to the low thermal conductivity of the soil surrounding the SBGHE. The most recently developed SBGHE is the underground thermal battery (UTB), which was introduced by the researchers from Oak Ridge National Laboratory [14,15]. A UTB is comprised of a tank filled with water buried in the shallow subsurface of the ground (less than $6 \mathrm{~m}$ deep), a helical heat exchanger immersed in the center of the tank and connected to a water source heat pump, and a small amount of enclosed phase change materials (PCMs), suspended in the annulus between the heat exchanger and the tank wall to provide the additional thermal capacity to the tank. A unique "water chimney" design utilizes the vertical temperature gradient of the heat exchanger coil (warm at the bottom and cold at top) to promote natural circulation within the tank, increasing the heat transfer between the tank water and the surrounding soil, heat exchanger coil, and the PCM, while maintaining a relatively uniform tank temperature.

The above-mentioned limitations for the TES tank and the recent development of SBGHE results in a novel hybrid product named dual-purpose underground thermal battery (DPUTB). It functions as both an SBGHE and a TES tank. It is installed in a vertical borehole much shallower than that used for typical VBGHE so that its installation cost can be reduced. Because the TES tank is installed in the ground, it does not occupy any floor or roof space. Moreover, compared with typical TES tanks installed above ground, the thermal loss from the TES tank of the DPUTB can be recovered by the SBGHE to improve the operational efficiency of the GSHP system. The DPUTB is a core component of a novel building thermal system that integrates a dual source (air and ground) heat pump with the DPUTB. In addition to high energy efficiency, this system can shift electric load and provide flexibility for demand response. Therefore, it can cut the energy cost of a building by taking advantage of the TOU tariff. If aggregated on large scale, this system can provide ancillary services to the electric grid and becomes more valuable.

An accurate and computationally effective model is needed to predict the long-term performance of the DPUTB. This model shall account for the transient ground heat transfer resulting from the varying heat flux at the ground surface, the heat transfer from the DPUTB, and the large thermal mass of the ground. Besides, the phase changing process of the PCM needs to be accurately modeled to predict the performance of the TES tank. This first-of-this-kind model is essential to optimize the design of the DPUTB and to evaluate the performance of the TES integrated heat pump system. 
The structure of this report is as follows: Section 2 introduces the configuration of the DPUTB and its design parameters; Section 3 presents details of a two-dimensional (2D) dynamic numerical model of the DPUTB; Section 4 discusses the calibration of the 2D model with a detailed three-dimensional (3D) model created with commercial computational fluid dynamic software (FLUENT version 17.2); Section 5 is a parametric study of the DPUTB to determine key design parameters; Section 6 presents the simulated seasonal performance of a dual-source heat pump system integrated with the DPUTB. Section 7 summarizes the findings of this study.

\section{DPUTB CONFIGURATION}

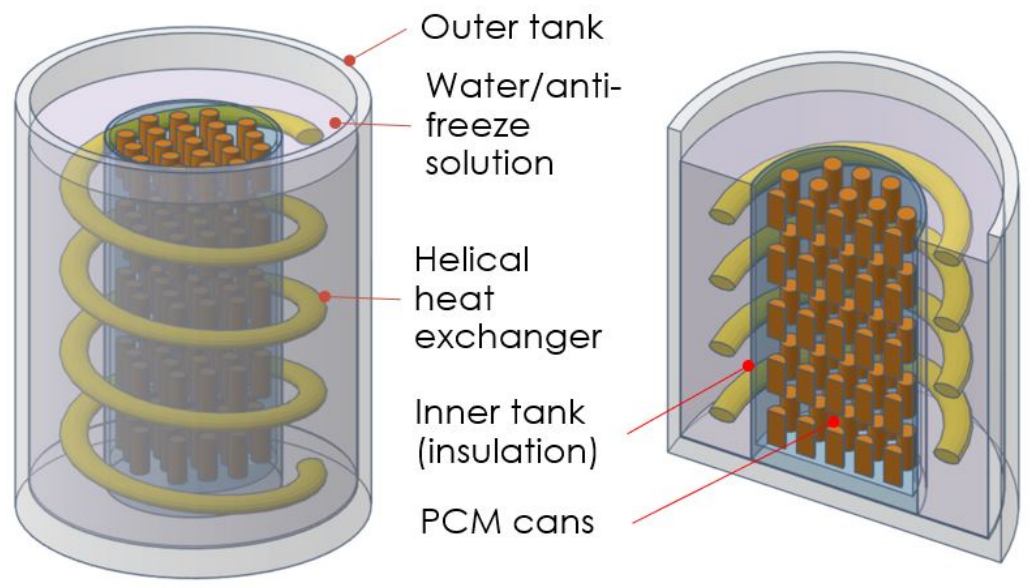

Figure 1. DPUTB tank configuration (not in scale)

Figure 1 shows the configuration of the DPUTB tank. The tank is installed in the shallow subsurface (less than 6 meters deep) of the ground. The dimension of the DPUTB tank is limited by the auger drilling technique. Augers are primarily used for general geomechanics exploration and drilling boreholes used for installing foundation piles or electric wire posts. For short-flight augers, the depth is limited to the length of the kelly on the drill rig, which is about 10 to 20 feet (3 to 6 meters) long [16].

The inner tank of the DPUTB works as a TES tank. PCM is applied to enhance its storage capacity. Multiple cylindrical cans filled with salt hydrate PCMs are immersed in the inner TES tank. The total volume of the PCM is determined by the desired energy storage capacity and the volumetric energy density of the selected PCM. To have better energy storage and heat transfer performance, the inner tank is structured as a stratified thermal storage tank. PCM cans are installed layer by layer with limited space in between. Diffusers/collectors are installed at the top and bottom of the tank to ensure uniform and steady flow of the heat transfer fluid (water) vertically along with the height of the tank. The heat transfer fluid flows through the gaps between the PCM cans to freeze or melt PCMs. A proper flow direction is selected to maintain thermal stratification in the tank. For example, to discharge cooling energy stored in the inner tank, the heat carrier fluid will flow from top to bottom and exit from the bottom of the inner tank. The flow direction is reversed when charging the inner tank (i.e. from bottom to top). The main advantage of incorporating TES in the DPUTB is that it does not occupy any floor or roof space of the building.

The outer tank of a DPUTB works as an SBGHE. A helical heat exchanger is installed in the outer tank that connects the DPUTB to the source side of the GSHP system. The helical heat exchanger is made with High-Density Polyethylene (HDPE), which is corrosion resistant in water and has reasonably good thermal conductivity. The flow direction of the heat transfer fluid in the helical heat exchanger is from bottom to top when rejecting heat to the outer tank and the flow direction is reversed when extracting heat from the outer tank. This arrangement is to create a reverse thermal stratification and introduce the natural convection movement of water in the outer tank. It will keep the outer tank temperature well mixed so that the change of tank temperature, as well as the leaving water temperature of the helical heat exchanger, in response to a heat/cool input is buffered by the thermal capacity of the entire water body in the outer tank. The water body can be cooled or warmed by other natural resources such as solar thermal and radiative 
sky cooling [29] to maintain the leaving fluid temperature from the outer tank, which enters the source-side of the heat pump, within a favorable range to ensure efficient operation of the heat pump. The outer tank is also made with HDPE.

The different functions of the inner and outer tanks result in a large temperature difference between the inner and outer tank water. Therefore, the inner tank should be insulated to reduce heat exchange between the two water bodies. The inner tank can be made with polyvinyl chloride (PVC), which is corrosion resistant and has a relatively low thermal conductivity compared with other plastics. The insulation of the inner tank will be discussed in Section 5 .

The default dimensions of a full-size DPUTB tank are listed in Table 1.

Table 1. Dimensions of a full-size DPUTB.

\begin{tabular}{lc}
\hline \multicolumn{1}{c}{ Dimension } & Value \\
\hline Tank height [mm] & 6000 \\
Inner tank inner diameter [mm] & 450 \\
Inner tank wall thickness [mm] & 8.6 \\
Outer tank inner diameter [mm] & 760 \\
Outer tank wall thickness [mm] & 10 \\
PCM can diameter [mm] & 30 \\
PCM can height [mm] & 85 \\
PCM can layer [-] & 50 \\
\# of PCM cans each layer [-] & 56 \\
Helical heat exchanger tube outer diameter [mm] & 33.4 \\
Helical heat exchanger tube wall thickness [mm] & 3 \\
Helical heat exchanger coil diameter [mm] & 720 \\
Total length of the helical heat exchanger coil [m] & 60 \\
\hline
\end{tabular}

\section{MODEL DEVELOPMENT}

\subsection{ASSUMPTIONS AND SIMPLIFICATIONS}

A two-dimensional (2D) numerical model is developed to simulate DPUTB's dynamic performance in charging and discharging operation. This model is to be integrated with other component models of a heat pump system to simulate the seasonal performance of the DPUTB and the overall heat pump system. The following simplifications are used to balance the accuracy and the computational effort of the model.

- The cylindrical DPUTB tank and the PCM cans are symmetric along their axis. Therefore the soil and the PCM cans are simplified as two-dimensional — axial and radial—in cylindrical coordinates.

- The thermophysical properties of the water, PCM, heat transfer fluid, and the soil surrounding the DPUTB are homogeneous in each control volume.

- Heat is transferred through conduction in PCM and the soil.

- The water in the outer tank has a uniform temperature. This is consistent with the lab tests and simulation results of a similar design (the Underground Thermal Battery) $[14,15]$.

- The thermal capacitances of the tank wall and the helical heat exchanger tube are neglected since their values are negligible compared with other components.

- The top of the DPUTB tank is perfectly insulated.

- The convection heat transfer in the outer tank water is negligible.

\subsection{SIMULATION DOMAIN AND BOUNDARY CONDITIONS}

The simulation domain of the 2D model is depicted in Figure 2. The DPUTB tank is installed $0.3 \mathrm{~m}$ below the ground surface and the depth of the simulated soil domain is $20 \mathrm{~m}$. The diameter of the soil domain is 20 times that of the DPUTB to ensure that the thermal impact of the DPUTB will not affect the boundary condition of the soil domain during an annual simulation. The boundary condition at the side surface of the soil domain is identical to the 
undisturbed soil temperature along with the depth. The boundary condition of the soil at the ground surface is the heat flux determined by the weather condition, vegetation condition, and ground surface temperature. The boundary condition at the bottom of the soil domain is assumed with a constant temperature gradient of $-25^{\circ} \mathrm{C} / \mathrm{km}$ [17] to account for the geothermal heat flux from the core of the earth. Other boundary conditions of the DPUTB include the flow rate and the inlet temperature of the heat transfer fluid in the outer tank and the inner tank.

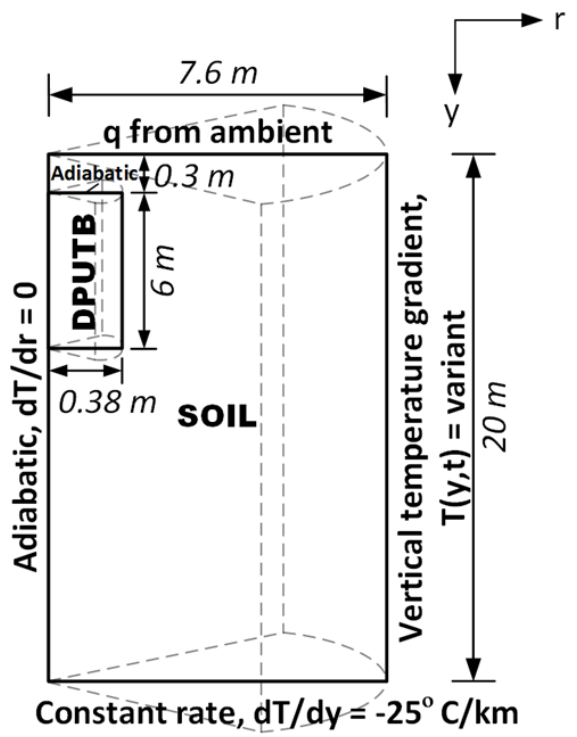

Figure 2. Diagram of simulation domain and boundary conditions

\subsection{GOVERNING EQUATIONS}

The governing equations for model each component of the DPUTB and the surrounding soil are presented in the following sub-sections.

\subsubsection{Inner Tank Water}

The inner tank water is modeled as a one-dimensional thermal mass. The temperature of the inner tank water $T_{w 1}(y, t)$ along the vertical axial direction (y) is expressed with Eq. (1):

$$
\left(\rho c_{p}\right)_{w 1} \frac{\partial T_{w 1}(y, t)}{\partial t}=\frac{\partial}{\partial y}\left(k_{w 1} \frac{\partial T_{w 1}(y, t)}{\partial y}\right) \pm \frac{\dot{m}_{w 1} c_{p, w 1}}{A_{w 1}} \frac{\partial T_{w 1}(y, t)}{\partial y}+\frac{n_{c a n} \Sigma \mathrm{d} q_{p c m-w 1}-\mathrm{d} q_{w 1-w 2}}{\mathrm{~d} V_{w 1}}
$$

If the inner tank water flow direction is from bottom to top, the sign of the second term on the right-hand side is negative. If the flow direction is reversed, the sign will be positive. If there is not any water flow in the inner tank (i.e., the water is kept still), the second term diminishes.

The heat transfer rate between PCM cans and the inner tank water $q_{p c m-w 1}$ is calculated with two equations: Eq. (2) is for heat transfer rate at PCM can's top or bottom surface; and Eq. (3) is for heat transfer rate at PCM can's side surface.

$$
q_{p c m-w 1}=\frac{T_{p c m}-T_{w 1}}{\frac{\mathrm{d} z_{p c m}}{2 k_{p c m}}+\frac{1}{h_{w 1-p c m}}} \mathrm{~d} A_{p c m}
$$




$$
q_{p c m-w 1}=\frac{T_{p c m}-T_{w 1}}{\ln \frac{r_{p c m}+\frac{1}{2} \mathrm{~d} r_{p c m}}{r_{p c m}} \frac{1}{2 \pi k_{p c m}}+\frac{1}{2 \pi\left(r_{p c m}+\frac{1}{2} \mathrm{~d} r_{p c m}\right) h_{w 1-p c m}}} \mathrm{~d} z_{p c m}
$$

The thermal resistance of PCM can's shell is neglected and it is assumed that the convective heat transfer coefficients $h_{w 1-p c m}$ for PCM can's side surface and the end surfaces are identical. The convection heat transfer on PCM can's surfaces is neglected when there is no water flowing through the inner tank. The convection heat transfer coefficient is determined by [18], as expressed in Eq. (4):

$$
h_{w 1-p c m}=\frac{k_{w 1} \mathrm{Nu}_{w 1-p 1}}{D_{h, w 1-p 1}}
$$

where,

$$
\begin{aligned}
& \mathrm{Nu}_{w 1-p 1}=\left\{\begin{array}{c}
3.66, \text { for laminar flow } \\
\frac{\left(\frac{f}{8}\right)\left(\mathrm{Re}_{w 1}-1000\right) \operatorname{Pr}_{w 1}}{1+12.7\left(\frac{f}{8}\right)^{\frac{1}{2}}\left(\operatorname{Pr}_{w 1} \frac{2}{3}-1\right)}, \text { for turbulent flow }
\end{array}\right. \\
& f=\left[0.79 \ln \left(\operatorname{Re}_{w 1}\right)-1.64\right]^{-2}
\end{aligned}
$$

The heat transfer rate between the inner tank water and the outer tank water $\left(q_{w 1-w 2}\right)$ can be calculated using Eq. (7):

$$
q_{w 1-w 2}=\frac{T_{w 1}-T_{w 2}}{\frac{1}{h_{w 1-w 2} 2 \pi r_{1}}+\ln \frac{r_{2}}{r_{1}} \frac{1}{2 \pi k_{\text {inner shell }}}} \mathrm{d} y_{w 1}
$$

where $r_{1}$ and $r_{2}$ represent the inner tank radius with and without shell thickness.

The convection heat transfer coefficient $h_{w 1-w 2}$ is assumed to be identical to $h_{w 1-p c m}$, and the heat transfer caused by convection is neglected when there is no water flowing through the inner tank.

The above governing equations are solved numerically. As mentioned in Section 3.1, the inner tank water is discretized into 50 identical control volumes along y-direction and each control volume has a layer of PCM cans. As previously stated, it is assumed that the water temperature in each control volume is uniform. The maximum time step used in the numerical scheme is 30 seconds.

\subsubsection{PCM Can}

As shown in Figure 1 and Figure 3, PCM cans are in contact with the inner tank water only. Because the water temperature in each control volume of the inner tank is assumed uniform, the thermal response of each PCM can in the same control volume is identical. The PCM can is modeled as a cylinder which is symmetric along the axis. Therefore, the temperature profile within a PCM can is determined using the 2D conduction heat transfer equation, as expressed in Eq. (8) in cylindrical coordinates:

$$
\left(\rho c_{p}\right)_{p c m} \frac{\partial T_{p c m}(r, z, t)}{\partial t}=\frac{1}{r} \frac{\partial}{\partial r}\left(k_{p c m} r \frac{\partial T_{p c m}(r, z, t)}{\partial r}\right)+\frac{\partial}{\partial z}\left(k_{p c m} \frac{\partial T_{p c m}(r, z, t)}{\partial z}\right)
$$

The above equation is discretization and solved numerically using an explicit finite difference scheme. The mesh size along with both radial and vertical directions is around $5 \mathrm{~mm}$. The corresponding maximum time step is around 15 seconds. The boundary condition of the PCM can is the heat transfer rate between the PCM can and the surrounding water. 


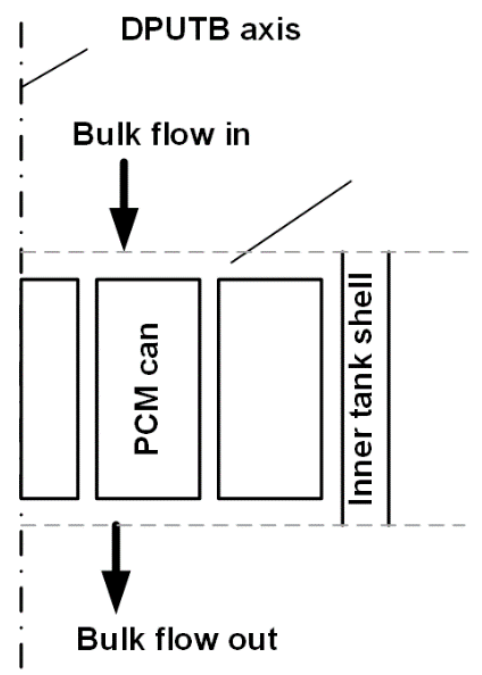

Figure 3. The layout of PCM cans in each control volume of the inner tank

For PCM phase change simulation, it is assumed that the phase change between solid and liquid happens within a small temperature range between $T_{m \text {,low }}$ and $T_{m \text {,high }}$ with no sub-cooling or hysteresis. When PCM's temperature is lower than $T_{m, l o w}$, it is in pure solid-state; when PCM's temperature is higher than $T_{m, h i g h}$, it is in a pure liquid state. Also, we assume that PCM's enthalpy has a linear relationship with its temperature [19]. Therefore, the phase change process can be accounted for by changing the specific heat and thermal conductivity based on PCM's temperature as expressed in Equations (9) and (10), respectively. Similarly, the liquid fraction of the PCM can be determined with Eq. (11).

$$
\begin{aligned}
& c_{p, p c m}=\left\{\begin{array}{c}
c_{p, p c m, s}, \text { if } T<T_{m, \text { low }} \\
\frac{c_{p, p c m, s}+c_{p, p c m, l}}{2}+\frac{\Delta H_{p c m}}{T_{m, h i g h}-T_{m, l o w}}, \text { if } T \\
c_{p, p c m, l} \text { if } T>T_{m, \text { high }}
\end{array} \in\left[T_{m, \text { low }}, T_{m, \text { high }}\right]\right. \\
& k_{p c m}=\left\{\begin{array}{c}
k_{p c m, s}, \text { if } T<T_{m, l o w} \\
k_{p c m, s}+\frac{k_{p c m, l}-k_{p c m, s}}{T_{m, h i g h}-T_{m, l o w}}\left(T-T_{m, l o w}\right), \text { if } T \in\left[T_{m, l o w}, T_{m, h i g h}\right] \\
k_{p c m, l}, \text { if } T>T_{m, \text { high }}
\end{array}\right. \\
& \lambda_{\text {pcm }}=\left\{\begin{array}{c}
0, \text { if } T<T_{m, \text { low }} \\
\frac{T-T_{m, \text { low }}}{T_{m, \text { high }}-T_{m, \text { low }}}, \text { if } T \in\left[T_{m, \text { low }}, T_{m, \text { high }}\right] \\
1, \text { if } T>T_{m, \text { high }}
\end{array}\right.
\end{aligned}
$$

The thermophysical properties of the PCM used in this study are listed in Table 2. These data are from a PCM manufacturer.

Table 2. Default thermo-physical properties of PCM.

\begin{tabular}{lc}
\hline \multicolumn{1}{c}{ Property } & Value \\
\hline Melting point $\left[{ }^{\circ} \mathrm{C}\right]$ & $9.35-9.5$ \\
Volumetric energy density $\left[\mathrm{J} / \mathrm{m}^{3}\right]$ & $300 \mathrm{e} 6$ \\
Thermal conductivity (liquid) $[\mathrm{W} / \mathrm{m} \mathrm{K}]$ & 0.54 \\
Thermal conductivity (solid) $[\mathrm{W} / \mathrm{m} \mathrm{K}]$ & 1.09 \\
Density $\left[\mathrm{kg} / \mathrm{m}^{3}\right]$ & 2200 \\
Specific heat (for both liquid and solid) $[\mathrm{J} / \mathrm{kg} \mathrm{K}]$ & 3140 \\
\hline
\end{tabular}




\subsubsection{Outer Tank Water}

As mentioned in Section 3.1, the entire outer tank water bulk is assumed to be one control volume (zero-dimension) that has a uniform temperature at any given time. The energy balance of the control volume leads to the following governing equation [Eq. (12)] for the temperature of the outer tank water $T_{w 2}(t)$ :

$$
\left(\rho c_{p}\right)_{w 2} \frac{\partial T_{w 2}(t)}{\partial t}=\frac{\Sigma \mathrm{d} q_{w 1-w 2}+\Sigma \mathrm{d} q_{h x-w 2}-\Sigma \mathrm{d} q_{w 2-s o i l}}{V_{w 2}}
$$

The heat transfer rate $q_{w 1-w 2}$ has been presented in Section 3.3.1. The heat transfer rate between the helical heat exchanger and the outer tank water $q_{h x-w 2}$ is expressed with Eq. (13):

$$
q_{h x-w 2}=\frac{T_{h x}-T_{w 2}}{\frac{1}{\pi D_{\text {inner tube }} h_{\text {hx }-w 2}}+\ln \frac{D_{\text {outer tube }}}{D_{\text {inner tube }}} \frac{1}{2 \pi k_{\text {tube }}}+\frac{1}{\pi D_{\text {outer tube }} h_{w 2-h x}}} \mathrm{~d} L_{h x}
$$

When there is no flow in the helical heat exchanger, the first term in the denominator of the right-hand side of the equation is neglected. The heat transfer coefficient $h_{h x-w 2}$ caused by the forced convection of the heat transfer fluid (water) in the helical heat exchanger can be determined by [20], as expressed with Eqs. 14 through 16.

$$
h_{h x-w 2}=\frac{k_{h x} \mathrm{Nu}_{h x-w 2}}{D_{\text {inner tube }}}
$$

where,

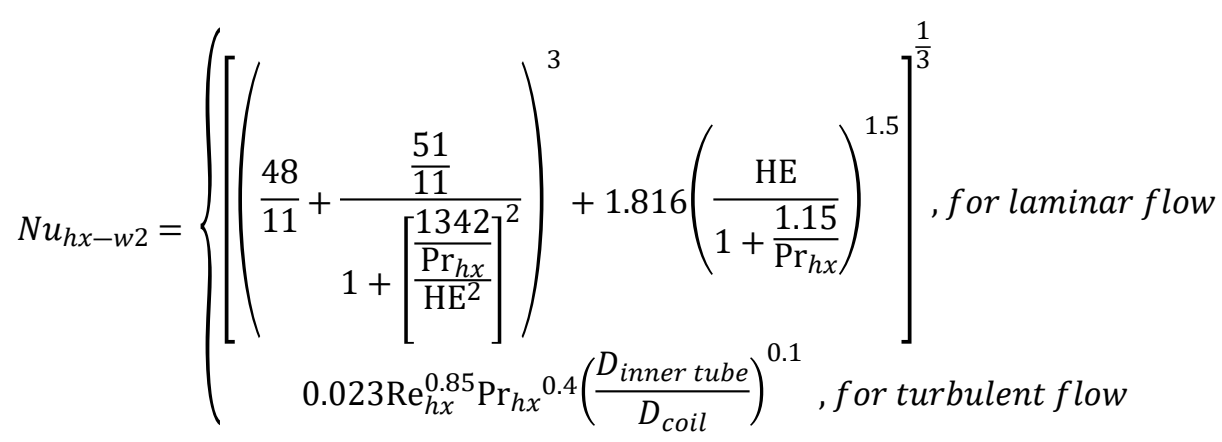

$$
\begin{aligned}
& \mathrm{HE}=\frac{\operatorname{Re}_{h x}\left[\frac{D_{\text {inner tube }}}{D_{\text {coil }}}\right]^{0.5}}{1+\left[\frac{\text { Pitch }_{\text {coil }}}{\pi D_{\text {inner tube }}}\right]^{2}}
\end{aligned}
$$

The heat transfer coefficient $h_{w 2-h x}$ caused by the natural convection of the outer tank water can be determined by [21], as expressed with Eqs. 17 and 18.

$$
h_{w 2-h x}=\frac{k_{w 2} \mathrm{Nu}_{w 2-h x}}{H_{\text {coil }}}
$$

where,

$$
\mathrm{Nu}_{w 2-h x}=0.0749 \mathrm{Ra}_{w 2}^{0.3421}
$$

When calculating the Rayleigh number, the interface temperature should be determined by an iteration method from an initial guess. This procedure drastically reduces the computational speed of the $2 \mathrm{D}$ model.

Similar to the PCM can sub-model, the heat transfer rate between the outer tank water and the surrounding soil $q_{w 2-\text { soil }}$ can be expressed with Eqs. 19 and 20: 


$$
\begin{aligned}
& q_{w 2-\text { soil }}=\frac{T_{w 2}-T_{\text {soil }}}{\frac{\mathrm{d} y_{\text {soil }}}{2 k_{\text {soil }}}+\frac{r_{4}-r_{3}}{k_{\text {outer shell }}}} \mathrm{d} A_{\text {soil }}, \text { for DPUTB bottom surface } \\
& q_{w 2-\text { soil }}=\frac{T_{w 2}-T_{\text {soil }}}{\ln \frac{r_{4}+\frac{1}{2} \mathrm{~d} r_{\text {soil }}}{r_{4}} \frac{1}{2 \pi k_{\text {soil }}}+\ln \frac{r_{4}}{r_{3}} \frac{1}{2 \pi k_{\text {outer shell }}}} \mathrm{d} y_{\text {soil }}, \text { for DPUTB side surface }
\end{aligned}
$$

where $r_{3}$ and $r_{4}$ represent the outer tank radius with and without shell thickness.

\subsubsection{Heat Transfer Fluid in the Helical Heat Exchanger}

A helical heat exchanger is implemented in the outer tank of the DPUTB that connects the DPUTB with the source side of the heat pump. When the ground heat exchanger function of the DPUTB is activated, heat transfer fluid will run through the helical heat exchanger and exchange heat with the outer tank water. The following differential equation [Eq. (21)] can be used to determine the temperature of the heat transfer fluid in the helical heat exchanger $T_{h x}(L, t)$ along its flow direction:

$$
\left(\rho c_{p}\right)_{h x} \frac{\partial T_{h x}(L, t)}{\partial t}=\frac{\partial}{\partial L_{h x}}\left(k_{h x} \frac{\partial T_{h x}(L, t)}{\partial L_{h x}}\right)-\frac{\dot{m}_{h x} c_{p, h x}}{A_{\text {inner tube }}} \frac{\partial T_{h x}(L, t)}{\partial L_{h x}}-\frac{\mathrm{d} q_{h x-w 2}}{\mathrm{~d} V_{h x}}
$$

The methodology to determine the heat transfer coefficient $h_{w 2-h x}$ has been presented in Section 3.3.3. The heat transfer fluid in the helical heat exchanger is discretized into 6 identical control volumes along the flow path and the above differential equation is solved numerically with an explicit finite difference method. The maximum time step is 10 seconds to ensure numerical stability.

\subsubsection{Surrounding Soil}

As mentioned in Sections 3.1 and 3.2, the surrounding soil of the DPUTB is modeled as a 2D hollow cylinder in the cylindrical coordinate system, considering the ground surface heat flux and the sequential vertical soil temperature gradient. The governing equation of the temperature profile of the simulated soil domain is expressed as Eq. (22):

$$
\left(\rho c_{p}\right)_{\text {soil }} \frac{\partial T_{\text {soil }}(r, y, t)}{\partial t}=\frac{1}{r} \frac{\partial}{\partial r}\left(k_{\text {soil }} r \frac{\partial T_{\text {soil }}(r, y, t)}{\partial r}\right)+\frac{\partial}{\partial y}\left(k_{\text {soil }} \frac{\partial T_{\text {soil }}(r, y, t)}{\partial y}\right)
$$

The above equation is discretized and solved numerically. The mesh size is $10 \mathrm{~cm}$ along both radial and vertical directions. The corresponding maximum time step is around 900 seconds. The heat transfer rate between the soil and the DPUTB and the boundary condition at the bottom of the soil domain have been explained in previous sections. Two other boundary conditions need to be further discussed: the ground surface heat flux and the vertical soil temperature gradient.

\subsubsection{Ground surface heat flux}

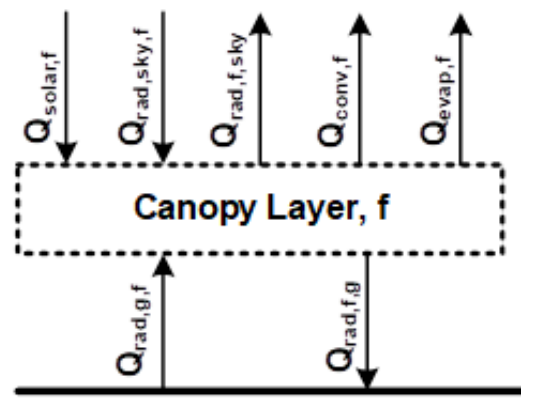

Ground Surface,g 
Figure 4. Heat flux at the ground surface

The method to determine the heat flux at the ground surface is adopted from the study by Xing and Spitler [22]. The vegetation above the ground surface is simulated as a canopy, which influences the solar radiation to the ground, as shown in Figure 4. For residential buildings, the DPUTB can be installed in the backyard, so the vegetation is typically short grass. The net heat gain at the canopy layer is zero when assuming no thermal mass of the canopy layer, and it is a function of the canopy temperature $T_{f}$. The energy balance for the canopy layer can be expressed with Eq. (23):

$$
q_{\text {solar }, f}+q_{\text {rad,sky,f }}+q_{\text {rad,g,f }}-q_{\text {rad,f,sky }}-q_{\text {rad,f,g }}-q_{\text {conv }, f}-q_{\text {evap }, f}=0
$$

Detailed explanations for each term in the above equation are elaborated by Xing and Spitler [22]. By applying meteorological data and solving Eq. (22), the canopy temperature can be determined. Furthermore, the heat flux at the ground surface can be calculated, which is the net flux combining $q_{\text {rad,g,f }}$ and $q_{\text {rad,f,g }}$.

\subsubsection{Undisturbed soil temperature gradient}

The undisturbed soil temperature gradient is the soil temperature that is not influenced by the DPUTB or other underground heat sources, and it is the boundary condition at the side surface of the soil sub-model. It can be determined by combining the ground surface heat flux model (Section 3.3.5.1) and a one-dimensional numerical model of the soil domain along with its depth.

Differential equation under Cartesian coordinate for one-dimensional unsteady heat conduction without internal heat gain can be expressed with Eq. (24):

$$
\rho_{\text {soil }} c_{p, \text { soil }} \frac{\partial T_{\text {soil }}}{\partial t}=\frac{\partial}{\partial y}\left(k_{\text {soil }} \frac{\partial T_{\text {soil }}}{\partial y}\right)
$$

By numerically solving the above equation, the undisturbed soil temperature gradient can be determined.

\subsection{SOLUTION METHOD}

The DPUTB model integrates all the sub-models described above to calculate the tank water temperatures, heat transfer rates, and the liquid fraction of PCMs at each simulation time step. The governing equations of each component model are solved using an explicit finite difference method. As shown in Figure 5, at each finite time step, the heat transfer rates between each component can be calculated given boundary conditions and components' temperature profiles, and they are assumed constant during this finite time step. After that, the energy balance equations of each component at this time interval can be solved explicitly, and the components' temperature profiles for the next time step can be determined. The updated temperature profiles are then used for the heat transfer rate calculation for the next time step. This process continues until the end of the user-specified simulation period. 


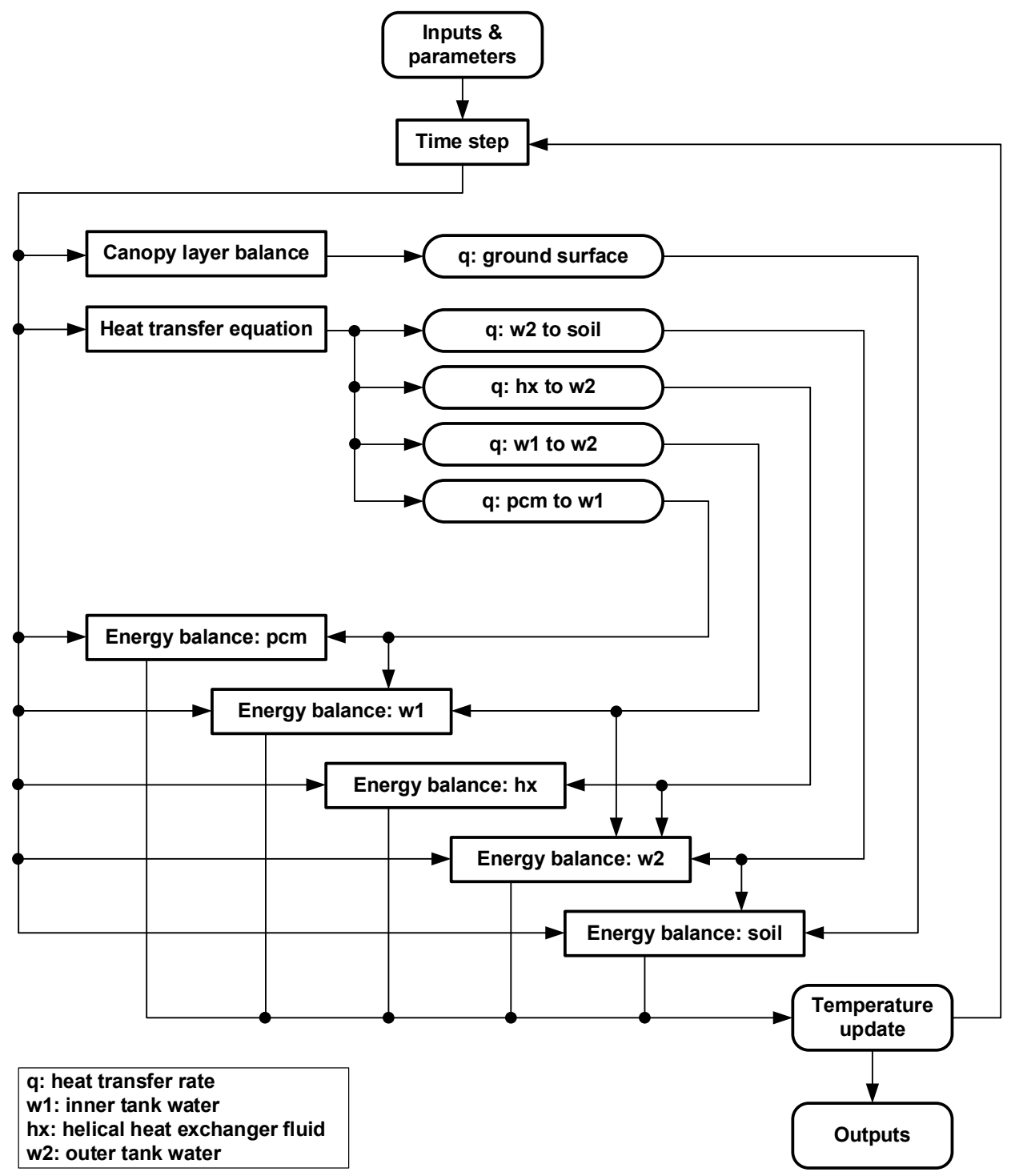

Figure 5. Flow chart of the calculation procedure of the 2D DPUTB model

\section{MODEL CALIBRATION}

\subsection{D MODEL DEVELOPMENT}

A 3D numerical model of the DPUTB has been developed to perform detailed heat transfer and fluid dynamics analysis of the DPUTB. Figure 6 shows the schematic view of the 3D model. In this model, an outer tank with $6.7 \mathrm{~m}$ length and $0.72 \mathrm{~m}$ diameter is filled with water. The outer tank is installed in the ground, which is not shown in Figure 6 . The simulated ground domain has $8 \mathrm{~m}$ length and $7.2 \mathrm{~m}$ diameter to ensure adiabatic boundary condition. A helical heat exchanger is installed in the outer tank. The heat exchanger is made with a $0.0225 \mathrm{~m}$ diameter HDPE pipe. The helical coil has a $0.7 \mathrm{~m}$ and a $0.24 \mathrm{~m}$ pitch between the turns. The lower end of the helical heat exchanger is connected to an adiabatic straight tube standing from the bottom to the top of the tank. The inner tank is $6.7 \mathrm{~m}$ long with a $0.47 \mathrm{~m}$ diameter. There are two $0.0225 \mathrm{~m}$ diameter openings in the inner tank to allow water flows in and out of the inner tank. One of the openings is at the top of the inner tank and the other is at the bottom. In the cooling discharge operation, warm water is injected into the inner tank from the opening at the top; and cold water flows into the inner tank from the opening at the bottom in the cooling charge operation. This switch of inlet helps to keep the temperature 
stratification in the inner tank for cooling energy storage. Forty-six cylinders filled with PCM are suspended in the center of the inner tank. The diameter and the length of each cylinder are $0.035 \mathrm{~m}$ and $3.8 \mathrm{~m}$, respectively.

The details of the 3D model, including governing equations and boundary conditions, can be found in the paper [14], where the 3D CFD UTB model has been validated by experimental data. A commercial code, ANSYS/FLUENT (v 17.2) was used to build the model and conduct the simulations. To account for the natural convection movement of water in the inner and outer tanks, a feature of ANSYS/FLUENT for modeling the gravity change of liquid was utilized. A piecewise-linear water density was defined in the model by using the property from NIST Chemistry WebBook [23]. A standard $k-\varepsilon$ model was used to model the turbulence flow in the tanks as well in the helical heat exchanger. The water flowing on the surface of PCM cans was defined as laminar flow due to the low speed of water flow. A built-in "Solidification \& Melting" model in FLUENT was utilized to model the solidification and melting of PCM in the DPUTB. A user-defined function (UDF) was developed to add the external load to the outer tank. The code first reads the temperature at the outlet of the helical heat exchanger, then calculates the temperature increase based on, the read temperature, flow rate, and external thermal load, finally assigns the calculated temperature to the inlet of the helical heat exchanger for the next time step simulation. The UDF code was compiled and implemented as the thermal boundary condition of the helical heat exchanger inlet in FLUENT. To avoid divergence, the simulation was running initially in a small time step (1 s). After $60 \mathrm{~s}$ simulation time, a larger time step $(20 \mathrm{~s})$ was used in the rest simulation.

The 3D model was used to simulate the short-term (8-hour) performance of the DPUTB under the following four scenarios, which represent the 4 typical working conditions of the DPUTB. The simulation results of the 3D model for the four cases are used to calibrate the $2 \mathrm{D}$ model in the next section.

- Case A: charge the inner tank with $5{ }^{\circ} \mathrm{C}$ inlet water temperature at $11.2 \mathrm{l} / \mathrm{m}(3 \mathrm{gpm})$ flow rate, and in the meanwhile reject $4.375 \mathrm{~kW}$ heat to the outer tank. This case represents the simultaneous space cooling and cooling storage operation of a GSHP integrated with the DPUTB.

- Case B: charge the inner tank with $5{ }^{\circ} \mathrm{C}$ inlet temperature at $11.2 \mathrm{l} / \mathrm{m}(3 \mathrm{gpm})$ flow rate without rejecting any heat to the outer tank. This case represents the cooling storage operation of the inner tank using an ASHP.

- Case C: discharge the inner tank with $14^{\circ} \mathrm{C}$ inlet water temperature at $11.2 \mathrm{l} / \mathrm{m}(3 \mathrm{gpm})$ flow rate without rejecting any heat to the outer tank. This case represents the discharge operation of the inner tank for providing space cooling.

- Case D: after the inner tank is fully charged (at the end of Case B), stop charging the inner tank and reject $4.375 \mathrm{~kW}$ heat to the outer tank. This case represents the standby mode of a fully charged inner tank to assess the thermal loss from the inner tank before discharging stored thermal energy.

Figures 7 and 8 show simulation predicted tank temperatures in Case A. To visualize the temperature distribution in the outer tank, Figure 7 illustrates a section view of the DPUTB by cutting off a quarter of the outer tank. The temperature profiles are depicted in the two cutting planes of the outer tank. Note that the difference between the maximum and minimum values of the legend in Figure 7 is only $0.5 \mathrm{~K}$, so there is a very small temperature difference (about $0.5 \mathrm{~K}$ ) in the outer tank water. It is because the hot water injected at the bottom of the tank warms the water there and then the lighter warm water at the bottom moves up to the top by the buoyancy force, which creates a natural convection movement of water in the entire outer tank and well-mixed water temperature. Figure 8 illustrates the temperature profile in the cross-section of the inner tank along the X-Y plane. As depicted in Figure 8, the temperature span between the top and the bottom of the inner tank is more than $4 \mathrm{~K}$, indicating significant temperature stratification in the inner tank. It is because the cold water flows in at the bottom of the inner tank at a low speed and does not generate natural convection movement in the inner tank. 


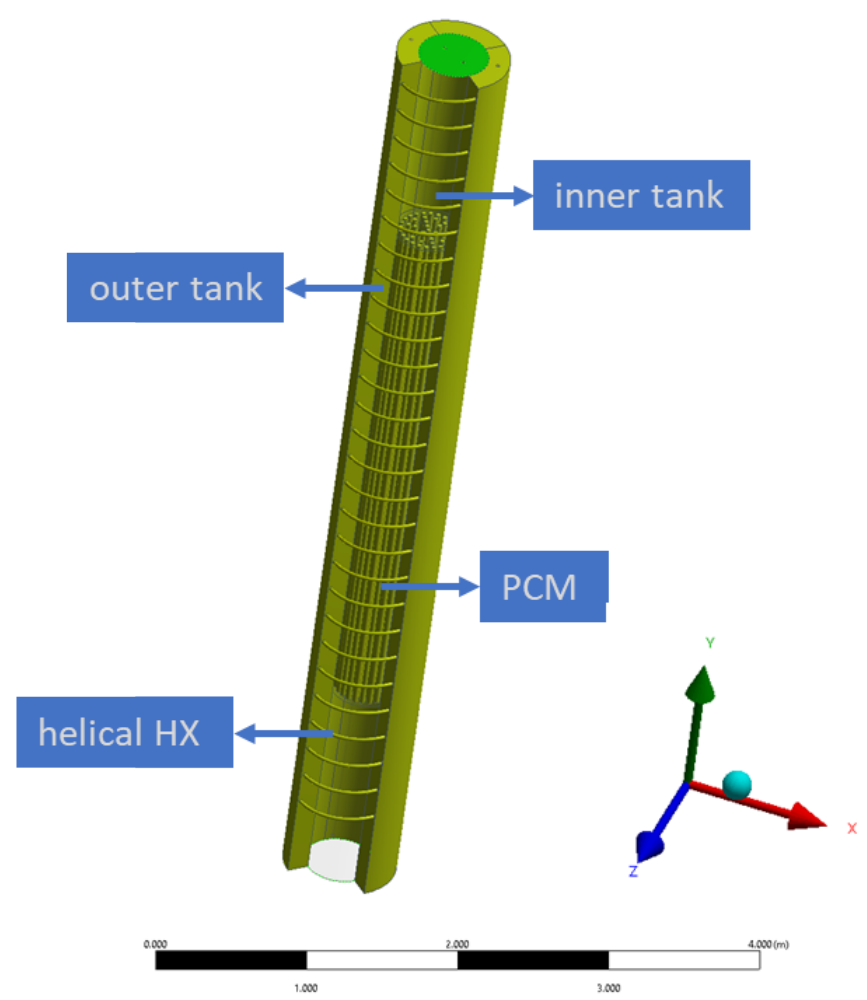

Figure 6. Schematic view of the 3D model of DPUTB
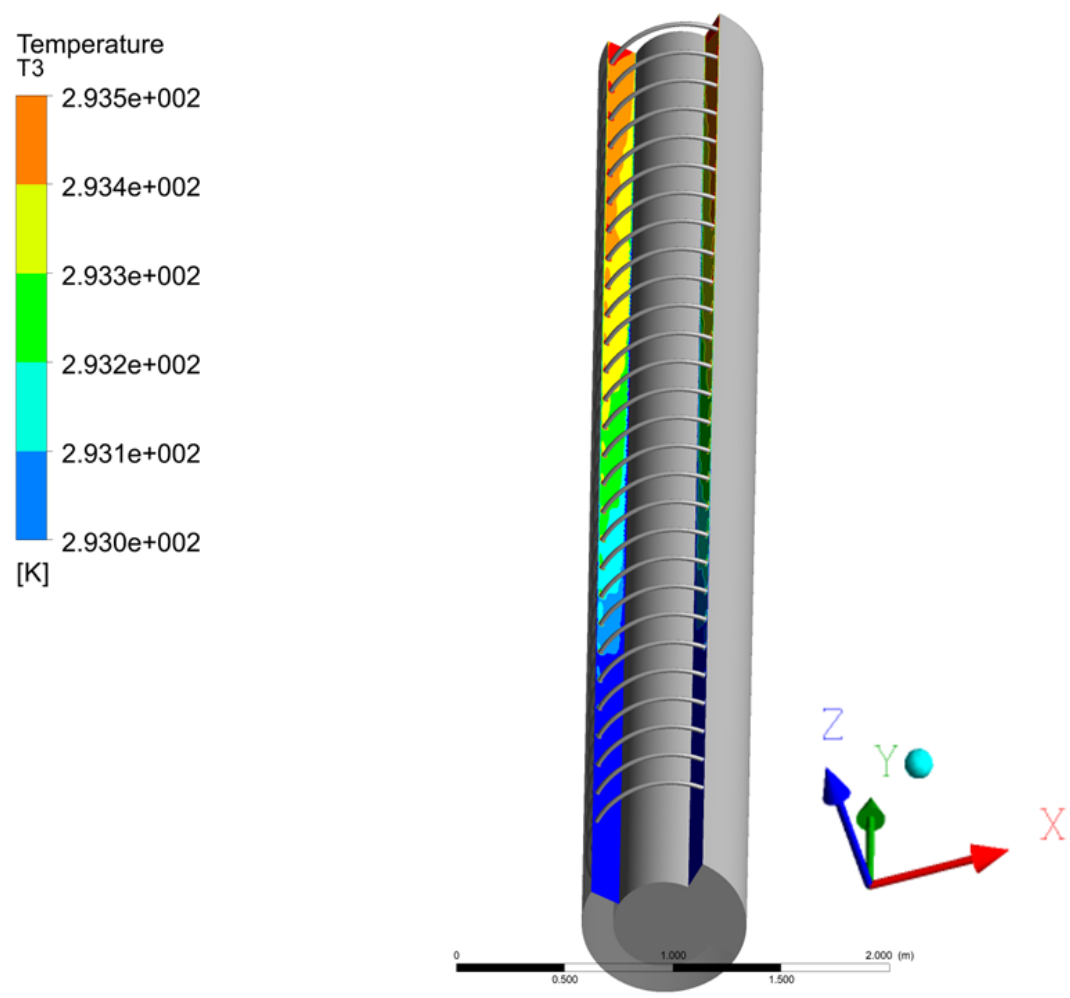

Figure 7. The temperature profiles of the outer tank 


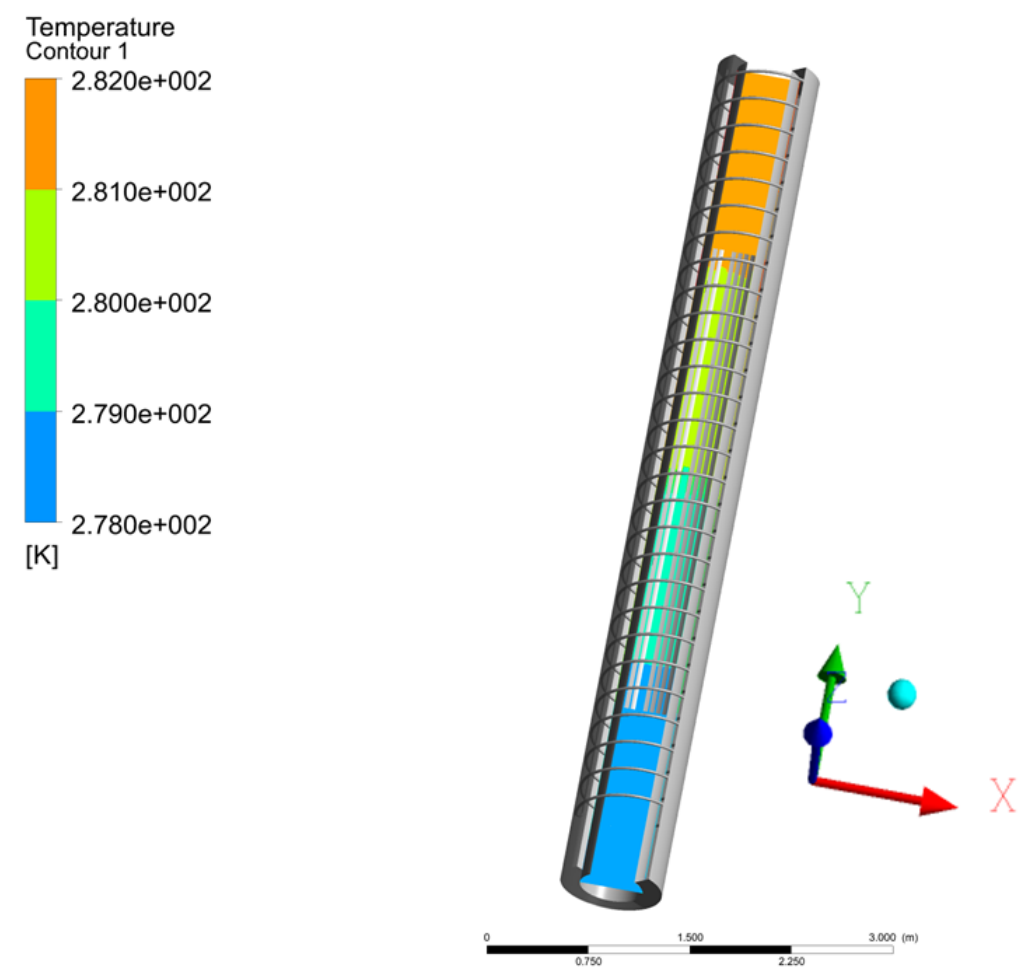

Figure 8 . The temperature profile of the inner tank

\subsection{D MODEL CALIBRATION}

The 2D model is used to predict the performance of the DPUTB under the Case A scenario. Its simulation results are compared with that predicted by the 3D model. As shown in Figure 9, there are some discrepancies in the simulation results of the two models. The discrepancies are due to two reasons. The first is the slightly different configurations of the PCM cans modeled in the two models. Due to the complexity and large scale of the simulation domain, and the computation limits of the computer running the 3D model, the PCM cans are modeled in the 3D model as a group of long tubes and there are two small water bodies in the inner tank below and on top of the PCM tubes (Figure 6). However, in the 2D model, multiple short PCM cans are evenly distributed along the vertical direction, and the PCM can be charged or discharged right after the operation begins. Compared with the distributed configured modeled in the 2D model, the charging and discharging of the PCM in the 3D model are delayed until the inlet water pushes through the water body before the PCM tubes. It can be seen clearly in Figure 9f. The different configurations of PCM cans also result in a delayed response of the inner tank outlet temperature in the 3D model, as shown in Figure 9e.

The second reason is the uncertainties of the convection heat transfer coefficients in the inner tank and the helical heat exchanger, which are estimated in the 2D model based on empirical equations, as discussed in Section 3. The comparison results indicate that the 2D model underestimates the heat transfer rate between the inner and outer tanks (Figure 9a), and overestimates the thermal resistance of the helical heat exchanger. As a result, the heat transfer rate between the outer tank and the surrounding soil (Figure 9b) and helical heat exchanger inlet and outlet temperatures (Figure 9c and 9d) predicted by the 2D model are higher than those predicted by the 3D model.

To more accurately determine the convection heat transfer coefficients, the 3D model results are used to calibrate the Nusselt numbers used in the $2 \mathrm{D}$ model. Through a trial and error process, $\mathrm{Nu}_{w 1-p 1}$ (between inner tank water and the PCM cans) and $\mathrm{Nu}_{w 1-w 2}$ (between the inner tank water and the inner tank interior surface) are increased by 3.5 times from 3.66 to 16.47 , and $\mathrm{Nu}_{w 2-h x}$ (between the outer tank water and the exterior surface of the helical heat exchanger) is increased by 1 time. These adjustments significantly reduce the discrepancies between the results predicted by the 2D and the 3D models as shown in Figure 9. The discrepancies in the predicted temperatures are less 
than $0.5^{\circ} \mathrm{C}$, the discrepancies in the predicted heat transfer rate are less than $9 \%$, and the discrepancy in the predicted solid fraction is less than 0.05 .

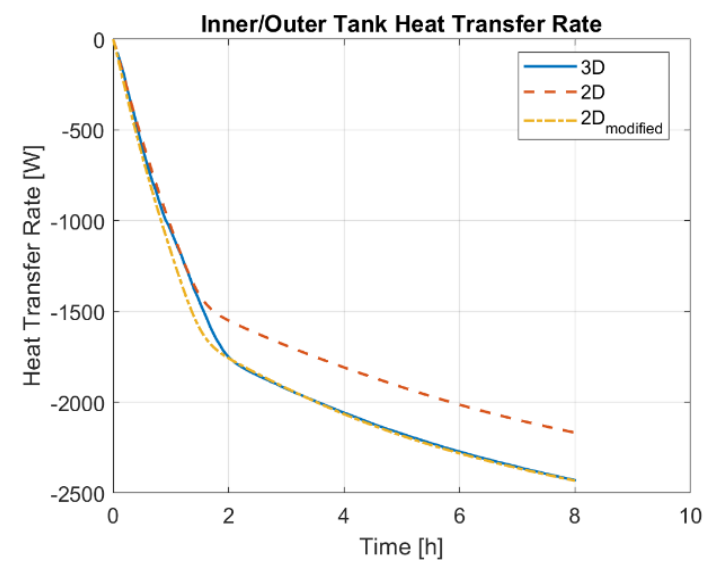

(a)

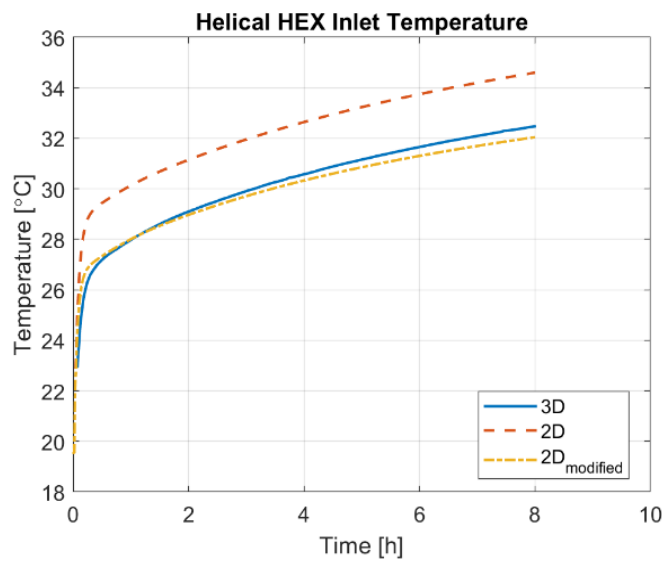

(c)

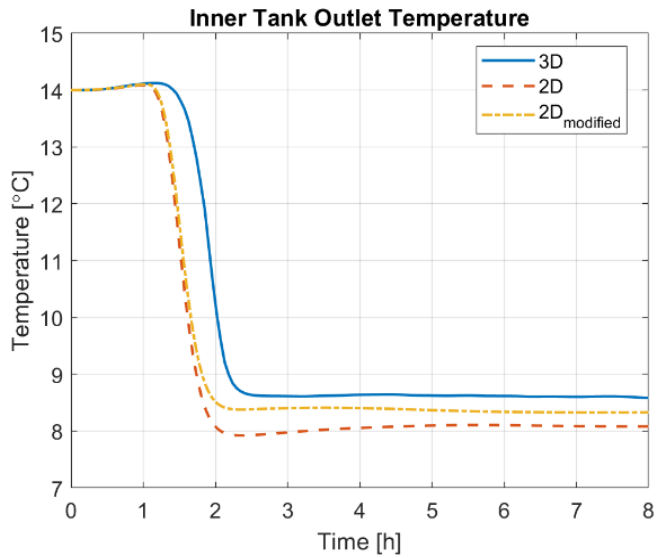

(e)

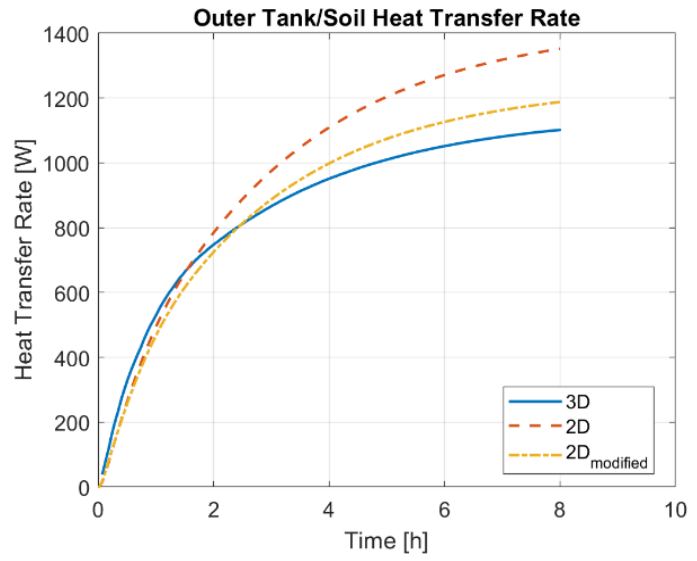

(b)

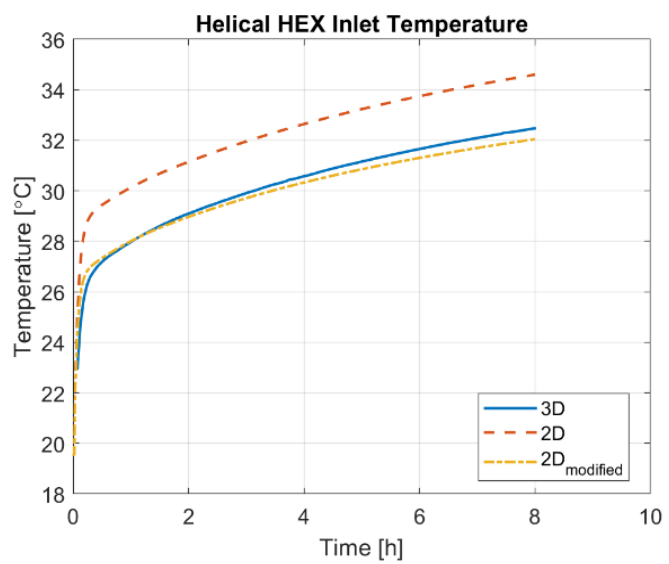

(d)

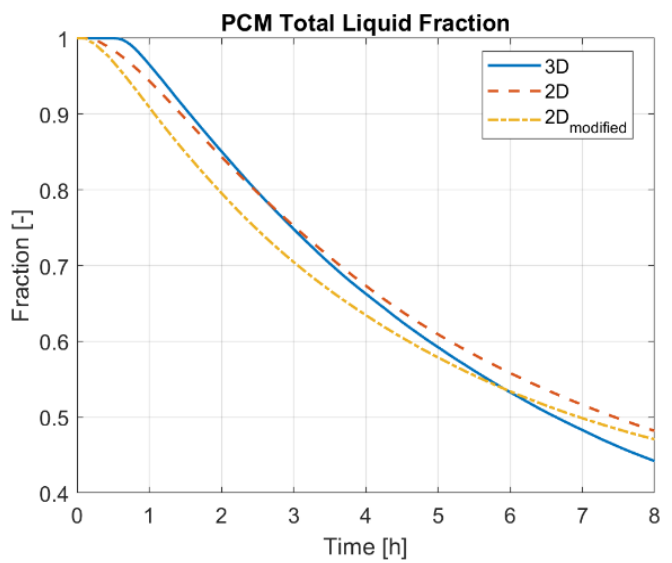

(f)

Figure 9. Comparison between the results of the $3 \mathrm{D}$ and the 2D models before and after calibration 
Although there are small discrepancies between the two models, the computation speed of the calibrated 2D model is about 1000 times faster than that of the 3D model. For example, simulating an 8-hour charging and discharging process of the DPUTB takes the 3D model 24 hours while the 2D model only needs 90 seconds.

\section{PARAMETRIC STUDY FOR THE INNER TANK DESIGN}

While the configuration of the outer tank is relatively fixed, there is some freedom in the design of the inner tank. This parametric study evaluates the sensitivity of several inner tank design parameters, including the inner tank shell thermal conductivity, PCM melting temperature, and the inner tank diameter. The results of this parametric study are used to identify a design for the inner tank that can provide the targeted thermal storage performance.

\subsection{INNER TANK DESIGN REQUIREMENT}

The inner tank is designed to act as a TES tank to store cooling and heating energy for load shifting in summer and winter. Because the duration of peak demand of the electric grid is usually 4-5 hours [24-26], the targeted performance of the inner tank is to provide $3.5 \mathrm{~kW}$ thermal power (equivalent to 1-ton cooling capacity) for 4 hours, which means $50.4 \mathrm{MJ}$ or $14 \mathrm{kWh}$ of thermal energy storage. If all this thermal energy is stored with the latent heat of the PCM, which has a $300 \mathrm{MJ} / \mathrm{m}^{3}$ energy density, $0.168 \mathrm{~m}^{3} \mathrm{PCMs}$ are needed.

Besides the storage capacity, the outlet water temperature of the inner tank during discharging operation is another key performance indicator. To provide sufficient latent and sensible cooling, the outlet water temperature from the inner tank should not be higher than $11^{\circ} \mathrm{C}$ during the discharging operation in summer. To provide effective heating, the outlet water temperature would be higher than $30^{\circ} \mathrm{C}$ during the discharging operation in winter. Besides, the charging time (for changing phase of all the PCMs in the inner tank) should be less than 8 hours to enable the diurnal operation of the TES.

\subsection{OPERATION SCENARIO}

The charging and discharging operation of the inner tank with several design variations is simulated with the 2D model of the DPUTB. For the first 8 hours, the inner tank is charged by circulating $5^{\circ} \mathrm{C}$ water at $11.31 / \mathrm{m}(3 \mathrm{gpm})$ flow rate from bottom to top. In the meanwhile, $4.375 \mathrm{~kW}$ heat (representing the condensing heat of a 1-ton GSHP with a COP of 4$)$ is rejected to the outer tank through the helical heat exchanger by circulating water at $11.3 \mathrm{l} / \mathrm{m}$ (3 gpm) flow rate. For the next 4 hours, the inner tank is discharged by circulating $14{ }^{\circ} \mathrm{C}$ water at $11.3 \mathrm{l} / \mathrm{m}(3 \mathrm{gpm})$ flow rate from top to bottom. At the beginning of the operation, anywhere in DPUTB and the simulated soil domain is at $14{ }^{\circ} \mathrm{C}$ and all the boundaries of the soil are adiabatic.

\subsection{RESULTS AND DISCUSSIONS}

\subsubsection{Inner Tank Shell Thermal Conductivity}

The thermal conductivity of the inner tank shell would affect the thermal loss quantity of the inner tank. For the baseline case, the inner tank shell $(8.6 \mathrm{~mm}$ thick) is made with PCV, which has a $0.19 \mathrm{~W} /(\mathrm{m}-\mathrm{K})$ thermal conductivity. In the alternative design, the inner tank shell is insulated with $8.6 \mathrm{~mm}$ thick Polystyrene, which has a $0.04 \mathrm{~W} /(\mathrm{m}-\mathrm{K})$ thermal conductivity. The simulation results of the baseline and the alternative design are shown in Figure 10. 


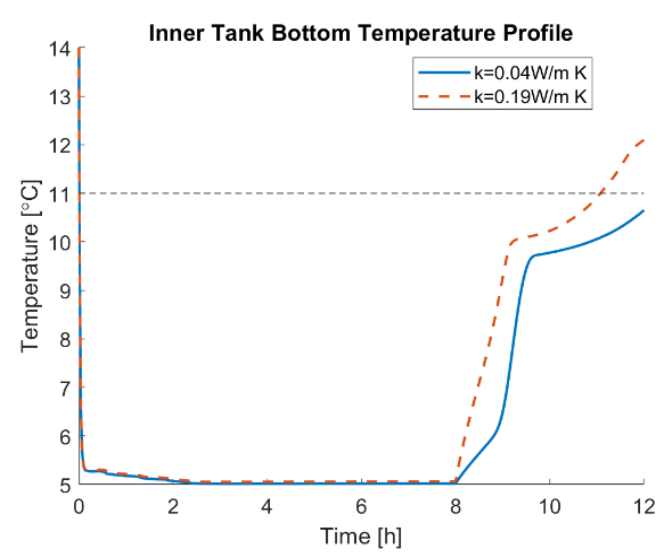

(a)

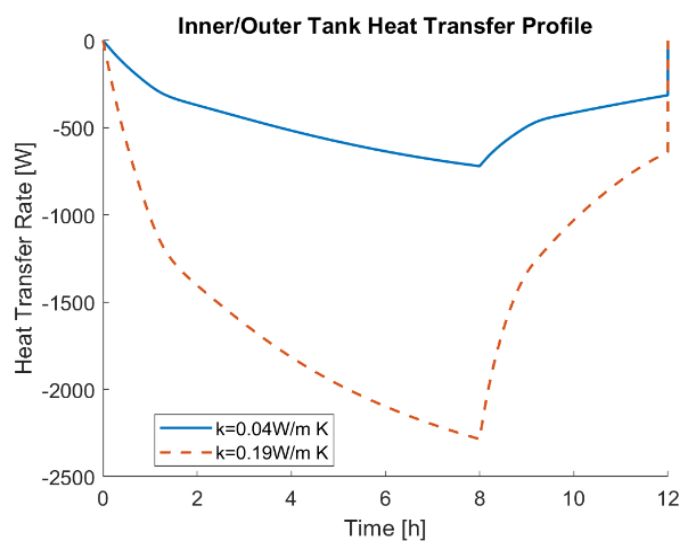

(c)

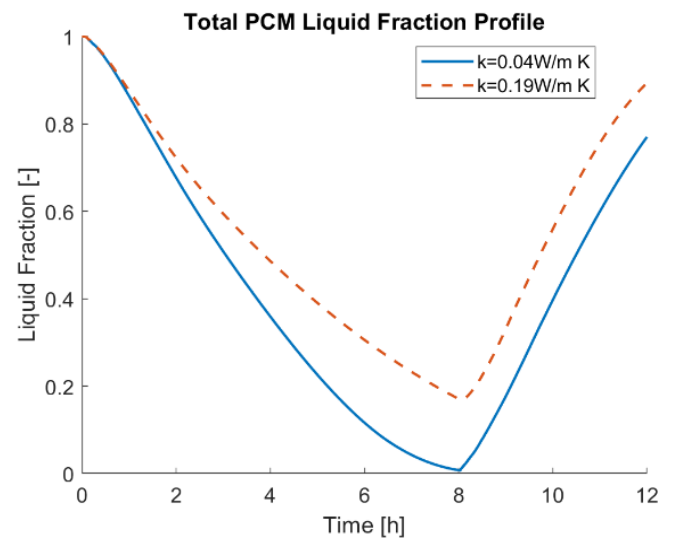

(b)

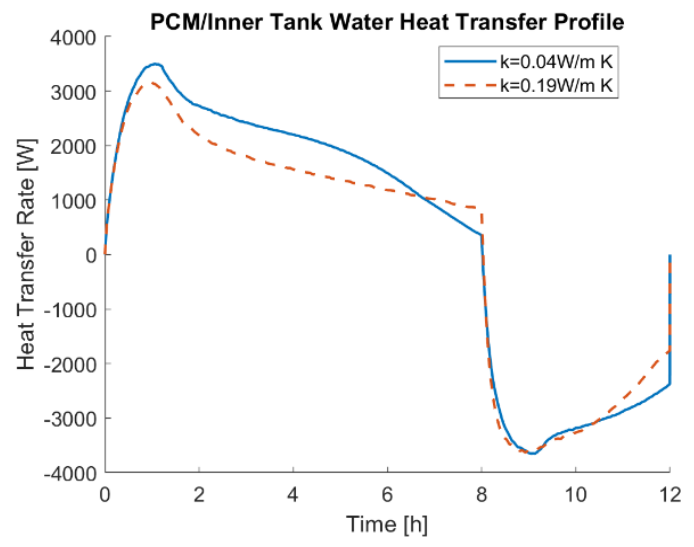

(d)

Figure 10. Parametric study result: inner tank shell thermal conductivity

The simulation results indicate that the thermal conductivity of the inner tank shell plays an important role in the thermal performance of the inner tank. PVC alone without any insulation is not an appropriate solution for the inner tank shell since it cannot keep the supply water temperature of the inner tank below $11^{\circ} \mathrm{C}$ during the 4-hour discharging period (Figure 10a). Figure 10c shows that the thermal loss of the inner tank is reduced by $75 \%$ in the alternative design because of the insulation. It ensures the PCM being fully charged during the first 8 hours (Figure 10b). Besides, the alternative design results in a more stable thermal energy discharge rate (Figure 10d). Therefore, the insulated inner tank shell is used in the following two parametric study cases.

\subsubsection{PCM Melting Temperature}

The PCM melting temperature is a critical parameter for thermal energy storage. In the baseline design, the PCM melting temperature is set at $9.35-9.5^{\circ} \mathrm{C}$, which is in the middle between the $5^{\circ} \mathrm{C}$ (cooling) charging water temperature and the $14^{\circ} \mathrm{C}$ (cooling) discharging water temperature. PCMs with a lower melting temperature may enhance the cooling discharging rate due to a larger temperature difference between the discharging water and the PCM. Therefore, an alternative design using a PCM with a $7.35-7.5^{\circ} \mathrm{C}$ melting temperature is simulated and its performance is compared with that of the baseline in Figure 11. 


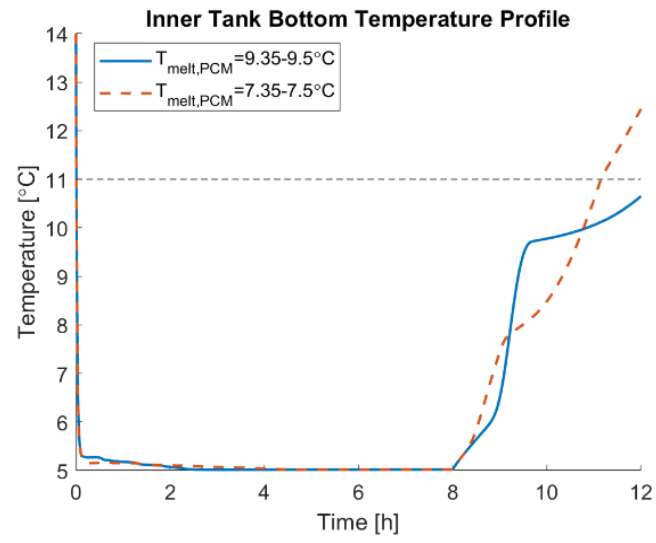

(a)

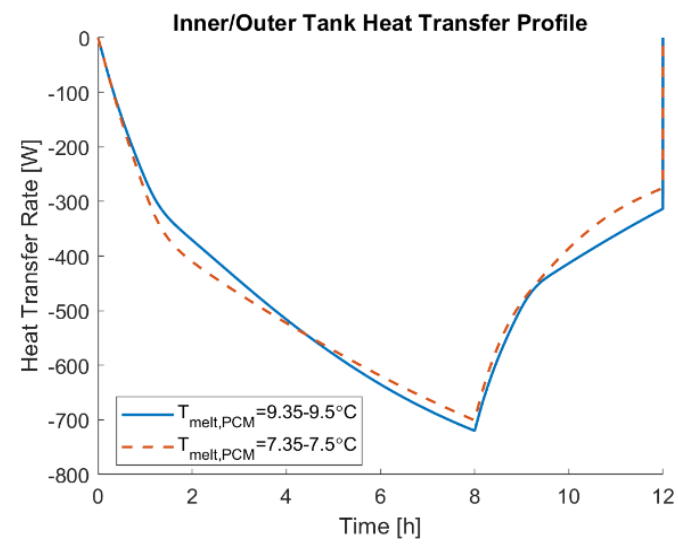

(c)

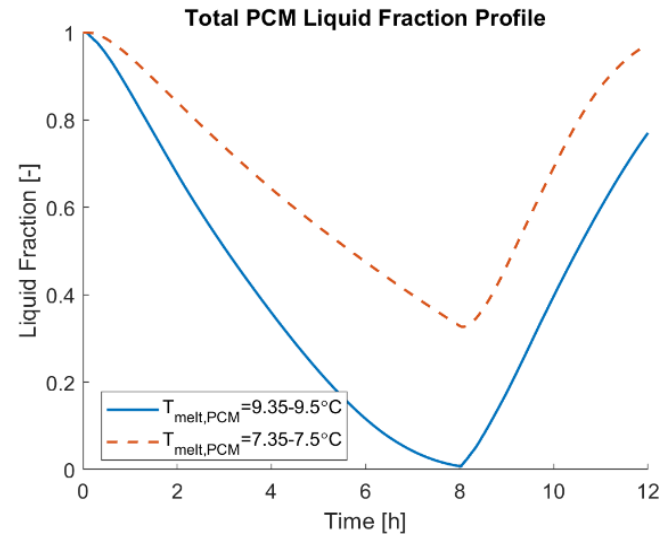

(b)

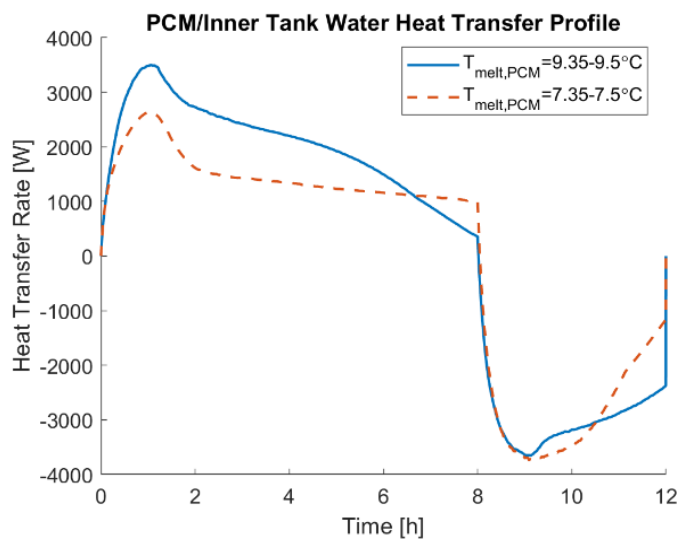

(d)

Figure 11. Parametric study result: PCM melting temperature

As shown in Figure 11b, the PCM with a lower melting temperature cannot be fully frozen during the 8-hour charging period. This is because the temperature difference between the charging water and the PCM becomes smaller. Although the inner tank bottom temperature (an approximation of the inner tank outlet temperature during discharging) resulting from using the lower melting temperature PCM is cooler than that of the baseline during at the first 2 hours of the discharging operation, it is higher than the baseline since then because a smaller amount of PCM is frozen during the charging period. As a result, the outlet temperature is not maintained below $11^{\circ} \mathrm{C}$ for 4 hours. The heat absorbed by the PCM with lower melting temperature drops quicker after 2 hours of discharging (Figure 11d). These results indicate that, with the same operation scenario, while lowering the PCM melting temperature improves direct cooling performance at the beginning, it discharges less total cooling energy within 4 hours.

\subsubsection{Inner Tank Shell Diameter}

The diameter of the inner tank can be adjusted within a range - the lower bound is determined by the required PCM volume for achieving the desired thermal storage capacity, and the upper bound is limited by the required heat capacity of the outer tank. The default inner tank diameter is $0.45 \mathrm{~m}$. Alternative designs with a smaller $(0.35 \mathrm{~m}$ diameter $)$ and a larger ( $0.55 \mathrm{~m}$ diameter) inner tanks are simulated and their performances are compared with that of the baseline design in Figure 12. 


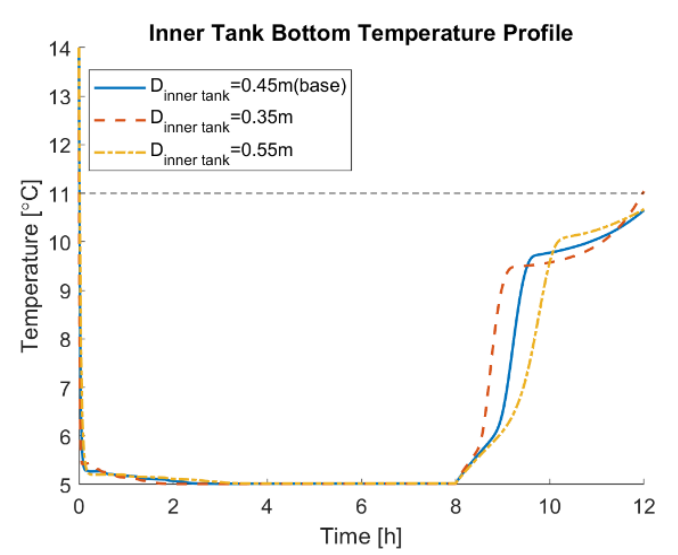

(a)

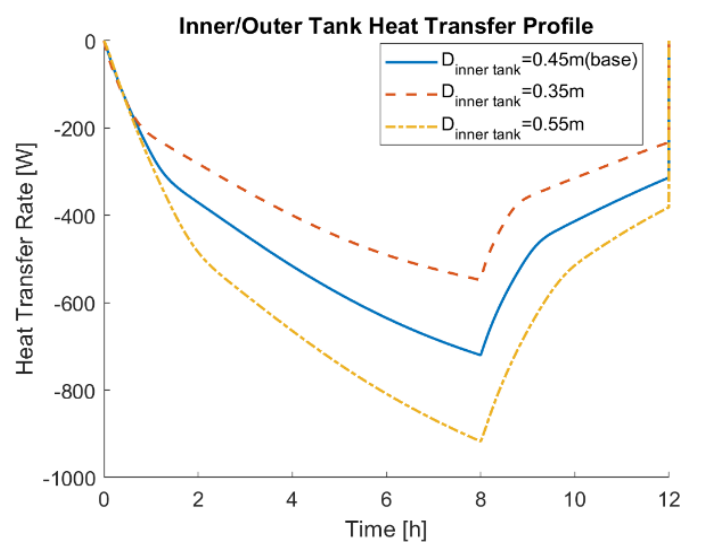

(c)

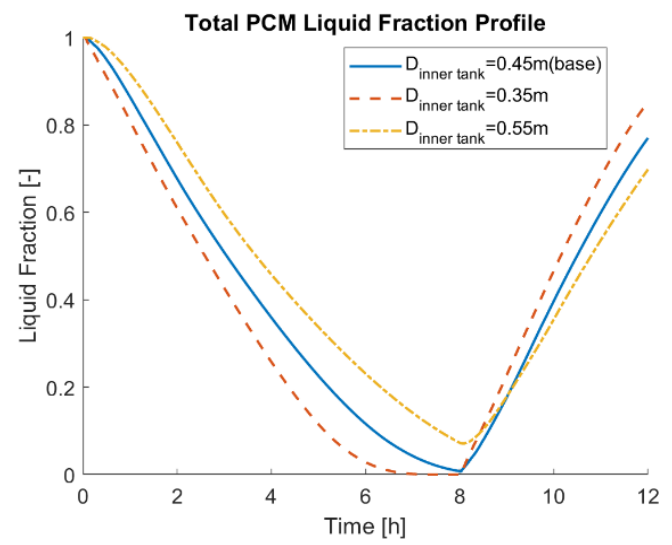

(b)

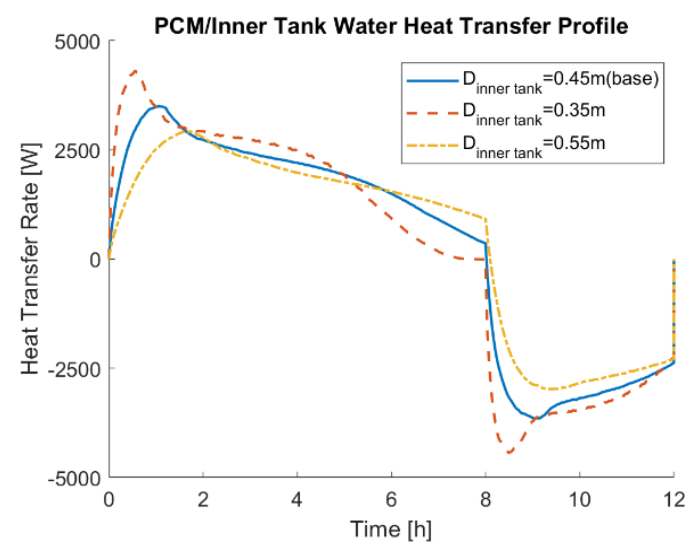

(d)

Figure 12. Parametric study result: inner tank shell diameter

Figure 12a shows that the overall charging and discharging performance resulting from the three different inner tanks are similar. Smaller inner tank results in higher cooling output at the early time of the discharging period and a slightly cooler outlet temperature during a later time when PCMs start melting. This is caused by two factors: (1) higher flow speed in the smaller inner tank increases the heat transfer rate between the PCM cans and the inner tank water; and (2) smaller inner tank surface area reduces thermal loss to the outer tank (Figure 12c). Figure 12b indicates that PCMs in the smaller inner tank can be fully frozen in a shorter time. PCMs in the large inner tank (0.55 $\mathrm{m}$ diameter) are not fully frozen after being charged for 8 hours and therefore the total discharged cooling from the PCMs during the 4hour discharging operation is smaller than that of the baseline and the smaller inner tank.

This parametric study indicates that the inner tank shell thermal conductivity and PCM melting temperature have significant impacts on the thermal storage performance of the inner tank. The inner tank shell thermal conductivity should be as low as $0.04 \mathrm{~W} /(\mathrm{m}-\mathrm{K})$. Using PCMs with melting temperatures lower than $9.35-9.5^{\circ} \mathrm{C}$ will decrease the cooling energy storage capacity given $5^{\circ} \mathrm{C}$ charging water temperature. The thermal storage performance is not significantly affected by the inner tank diameter, a $0.45 \mathrm{~m}$ diameter is selected because it allows full usage of the PCM's latent heat.

\section{SYSTEM SIMULATION}

The DPUTB model is coupled with simplified computer models of a dual-source heat pump (DSHP) and a singlefamily house to simulate the long-term performance of the integrated DPUTB and DSHP system as shown in Figure 13. The DSHP utilizes either ambient air or ground as its heat source/sink. It runs as an ASHP when the ambient air temperature is favorable for the heat pump to run efficiently. It switches to ground source when the ambient air temperature is too high in summer (or too low in winter). In this case, the source side of the GSHP is connected with 
the helical heat exchanger in the outer tank of the DPUTB, which extract heat from or reject heat to the outer tank water and eventually to the surrounding soil of the DPUTB. Using DSHP can reduce the thermal loads to the DPUTB so that less number of DPUTB is needed for a given building.

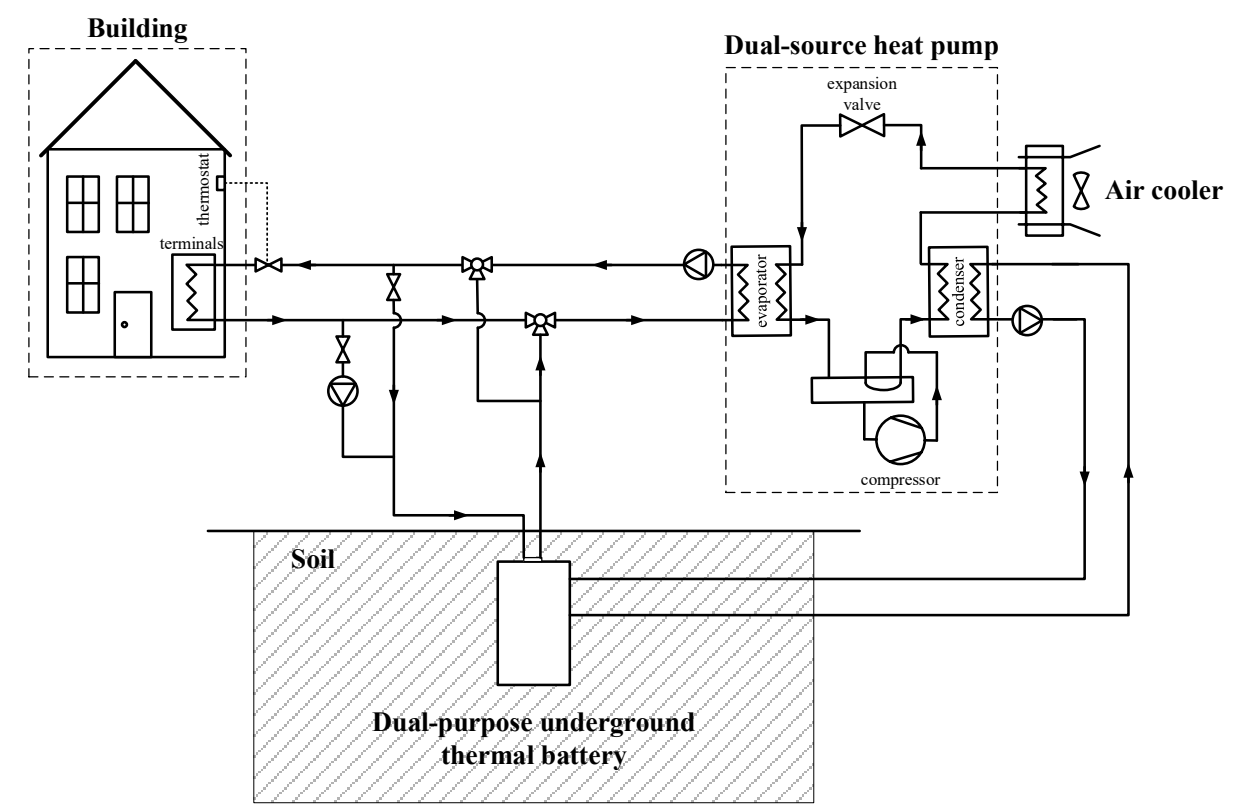

Figure 13. Diagram of an integrated DPUTB and DSHP system for a single-family house

\subsection{SYSTEM MODELING INFORMATION}

\subsubsection{Building}

The hourly thermal loads of a typical residential building in Knoxville, TN is predicted using the U.S. Department of Energy's prototype model [27] and the typical meteorological year 3 (TMY3 [28]) weather data of Knoxville, TN. The prototype building is a single-family detached house with $223 \mathrm{~m}^{2}$ air-conditioned floor space. An ASHP provides both space cooling and space heating to the building through a central constant volume air system. The nominal cooling capacity of the ASHP is 2-ton ( $7 \mathrm{~kW}$ ). Its nominal COP for cooling is 4.07 (at $35^{\circ} \mathrm{C}$ ambient air temperature) and its nominal COP for heating is 3.69 (at $8.3^{\circ} \mathrm{C}$ ambient air temperature). The ASHP uses a supplemental electric resistance heater to meet the heating demand when the ambient temperature is low (usually below $7.2^{\circ} \mathrm{C}$ ). The ASHP is turned on and off to maintain the room temperature between $22.2^{\circ} \mathrm{C}$ and $23.9^{\circ} \mathrm{C}$ year-round. The electricity end-use load profile (EULP) of the building resulting from the ASHP system is used as a baseline to be compared against the EULP resulting from using the integrated DSHP and DPUTB system.

\subsubsection{DSHP and DPUTB}

The DSHP is modeled as a combination of two conventional heat pumps: an AWHP for air source and a water-water heat pump (WWHP) for ground source. The curve fitting models for the AWHP and the WWHP are developed based on the heat pump models (type 927 and type 941) in TRNSYS 17 [20]. These heat pump models use performance curves of typical AWHP and WWHP units to predict their heating and cooling outputs and associated power consumption based on the inlet conditions from the condenser and evaporator. The nominal cooling and heating COPs of the AWHP and the WWHP are 4.0 and 5.0 $0^{1}$, respectively. The switch between AWHP and WWHP is according to

${ }^{1}$ The source-side entering fluid temperature at the rating condition for WWHP in heating and cooling operations are $0^{\circ} \mathrm{C}$ and $25^{\circ} \mathrm{C}$, respectively. 
the ambient temperature - in the cooling season, AWHP is used when the ambient air temperature is lower than $26.7^{\circ} \mathrm{C}$; in the heating season, AWHP is used when the ambient air temperature is higher than $5.0^{\circ} \mathrm{C}$. WWHP is used at other times.

The thermal energy storage capacity of the proposed system is equal to the total thermal load during the on-peak period of the design day (i.e., the hottest day in summer). It ensures that the stored thermal energy is adequate for providing space cooling during the entire on-peak period, thus the heat pump can be turned off to reduce electric demand. The capacity of the DSHP could be smaller than the peak cooling load of the building during a cooling season, but it is larger than the maximum cooling load during the off-peak period so that it can simultaneously cool the inner tank for storing sufficient cooling energy while providing space cooling during the off-peak hours. To meet the cooling loads of the simulated single-family house, two identical DPUTBs are needed, and the nominal cooling capacity of the DSHP is 1.75 -ton $(6.125 \mathrm{~kW})$, which is $12.5 \%$ smaller than the baseline ASHP.

\subsubsection{Electricity Rate}

A pilot Time of Use (TOU) electric tariff is used in this study. This TOU electric tariff named 'Schedule RD' was introduced by the Baltimore Gas and Electricity Company for residential customers who have installed smart meters (currently there is no certain pilot tariff in Knoxville, TN for residential buildings) [24]. According to this tariff, during summer (July 1 through September 30), the electricity retail price is 0.226 $\$ / \mathrm{kWh}$ between 14:00 and 19:00 on weekdays, which is defined as on-peak hours, and it is $0.0425 \$ / \mathrm{kWh}$ for other time (off-peak hours). During other seasons (October 1 through June 30), the peak hour is between 6:00 and 9:00 on weekdays, and the electricity price is $0.245 \$ / \mathrm{kWh}$, while for off-peak hours the price is $0.048 \$ / \mathrm{kWh}$.

\subsubsection{Control Strategy}

The integrated DSHP and DPUTB system can be operated in ten different modes, as listed in Table 3. To achieve specific goals (e.g., energy cost reduction, load leveling, etc.), different control strategies can be developed to determine the operation mode at a given time of a day. In this study, a rule-based control strategy is developed to shift the electric demand of the building from peak hours to off-peak hours so that it can take full advantage of the TOU electric tariff to reduce the energy cost of the building. The flow charts of this control strategy in cooling and heating seasons are shown in Figure 14.

Table 3. Operation modes of the integrated DSHP and DPUTB system

\begin{tabular}{llll}
\hline Mode & Building Load & Heat Pump Status & TES Status \\
\hline 1 & no & off & off \\
2 & yes & off & discharge \\
3 & yes & air-source & off \\
4 & yes & ground-source & off \\
5 & yes & air-source & charge \\
6 & yes & ground-source & charge \\
7 & yes & air-source & discharge \\
8 & yes & ground-source & discharge \\
9 & no & air-source & charge \\
10 & no & ground-source & charge \\
\hline
\end{tabular}




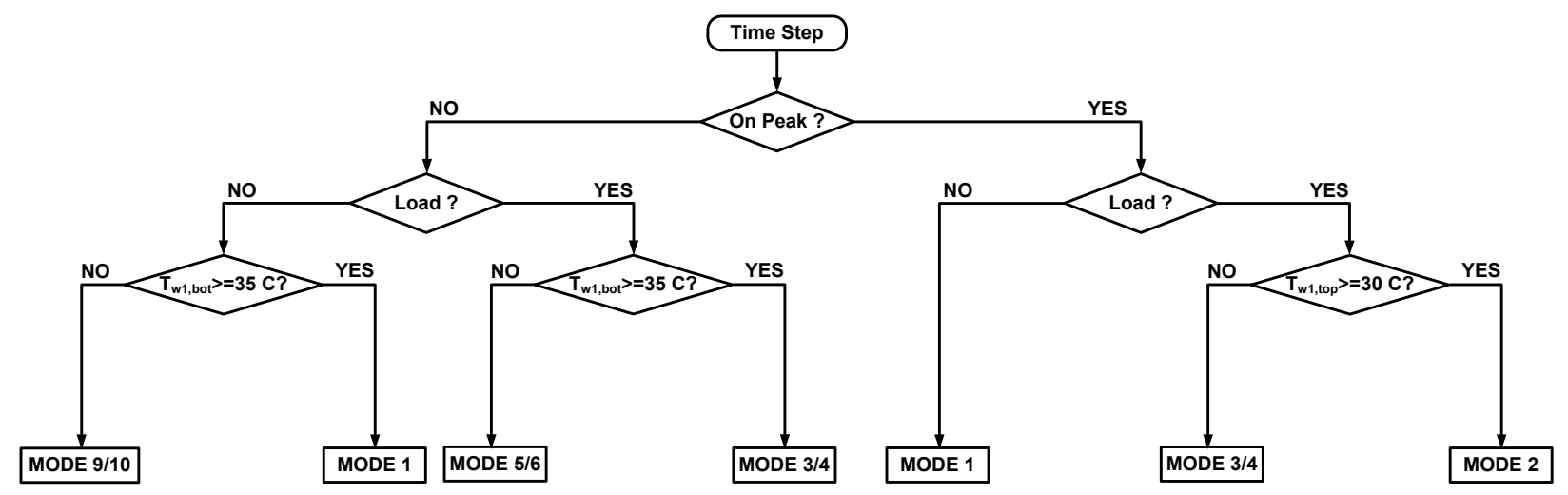

(a)

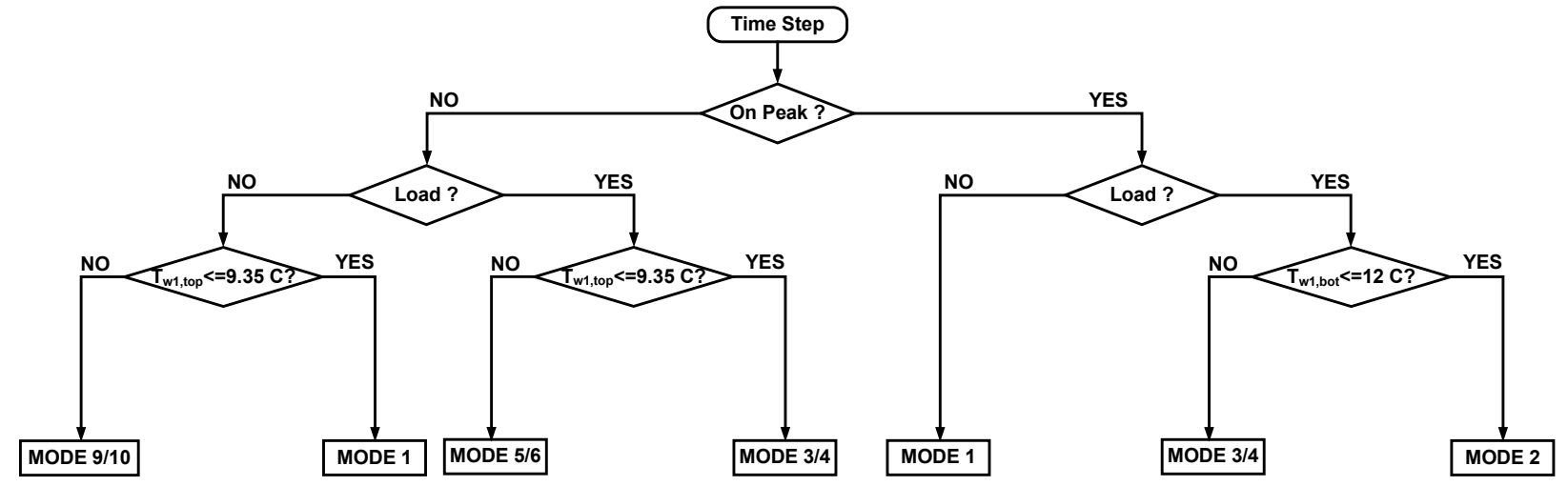

(b)

Figure 14. Control strategy for (a) heating season; and (b) cooling season

\subsection{RESULTS AND DISCUSSIONS}

\subsubsection{Cooling Season Performance}

The performance of the integrated DPUTB and DSHP system in July is simulated and some featured results for a single day (July 14) are shown in Figure 15. The shaded areas represent the on-peak period of the day. As shown in Figure 15a, DSHP is operated during the off-peak period to meet the thermal load of the building and to store cooling energy in the inner tank. When the ambient temperature (indicated by the yellow triangles) is lower than the predefined switching point $\left(26.7^{\circ} \mathrm{C}\right)$, ambient air is used as the heat sink of the heat pump. When the ambient air temperature is higher than the switching point at the mid of the day, the condensing heat from the heat pump is rejected to the outer tank of the DPUTB instead. The outlet water temperature of the helical heat exchanger in the outer tank of the DPUTB ( $T_{G H E, O u t}$ ), which is the entering water temperature of the heat pump, is maintained below $30^{\circ} \mathrm{C}$ during the day. It enables the heat pump to run at high efficiency (COP > 4.6). During the on-peak period, the stored cooling energy is discharged to meet the thermal load of the building, and the heat pump is completely turned off. The outlet water temperature of the inner tank $\left(T_{T E S, O u t}\right)$, indicated by the red circles, is below $11^{\circ} \mathrm{C}$ while meeting all the cooling load during the 5-hour on-peak period. Figure 15a also shows that the solid fraction (represented with the purple line) drops from 1 to 0.2 during the discharging period. It means that $80 \%$ of the solid PCM is melted during the on-peak period. Figure $15 \mathrm{~b}$ shows that the electricity demand during the on-peak period is significantly reduced, but the electricity demand during off-peak hours increases for charging the inner tank. It shows that the electricity demand for meeting the cooling demand of the building during the 5-hour peak period is shifted and distributed into the 19hour off-peak period. On the single day of July 14, the total power consumption during the on-peak period is reduced by $43 \%$ from $15.4 \mathrm{kWh}$ to $8.6 \mathrm{kWh}$. 


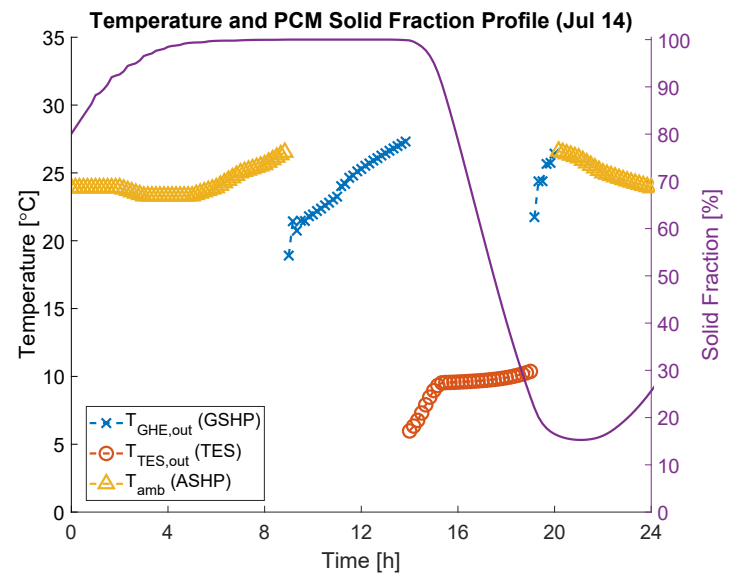

(a)

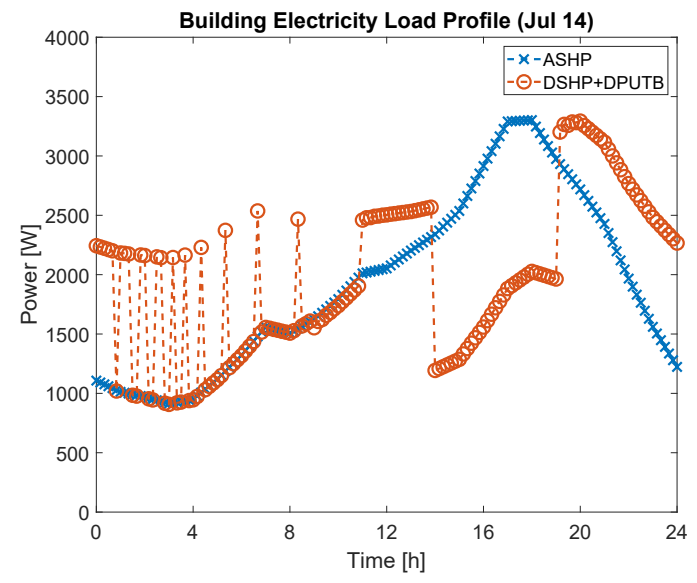

(b)

Figure 15. Featured system simulation results on July 14: (a) DPUTB and DSHP operating status; (b) building EULP resulting from the integrated DPUTB and DSHP system and the baseline ASHP system

The daily profiles of the $T_{T E S, O u t}$ during the on-peak period and PCM's solid fraction in July are illustrated in Figure 16 and Figure 17, respectively. As shown in these figures, $T_{T E S, O u t}$ is below $12^{\circ} \mathrm{C}$ during the discharging operation on most days except at the end of the on-peak period on 16th, 18th, 19th, and 20th day of July when the maximum $T_{T E S, O u t}$ reaches $13{ }^{\circ} \mathrm{C}$ and all the PCM is melted (solid fraction becomes zero). Figure 18 shows $T_{G H E \text {,Out }}$ in July when the DSHP rejects heat to the outer tank of the DPUTB. It can be observed from this figure that the DSHP rejects heat to the DPUTB more frequently in mid of July when the weather becomes hotter and the maximum $T_{G H E, O u t}$ in July is below $36^{\circ} \mathrm{C}$, at which the DSHP can run with a COP not less than 3.6. These results indicate that the current design and number of DPUTB can meet the thermal loads with expected performance - the electric load for meeting the cooling demand is shifted from the on-peak period to the off-peak period, and the TES is fully utilized.

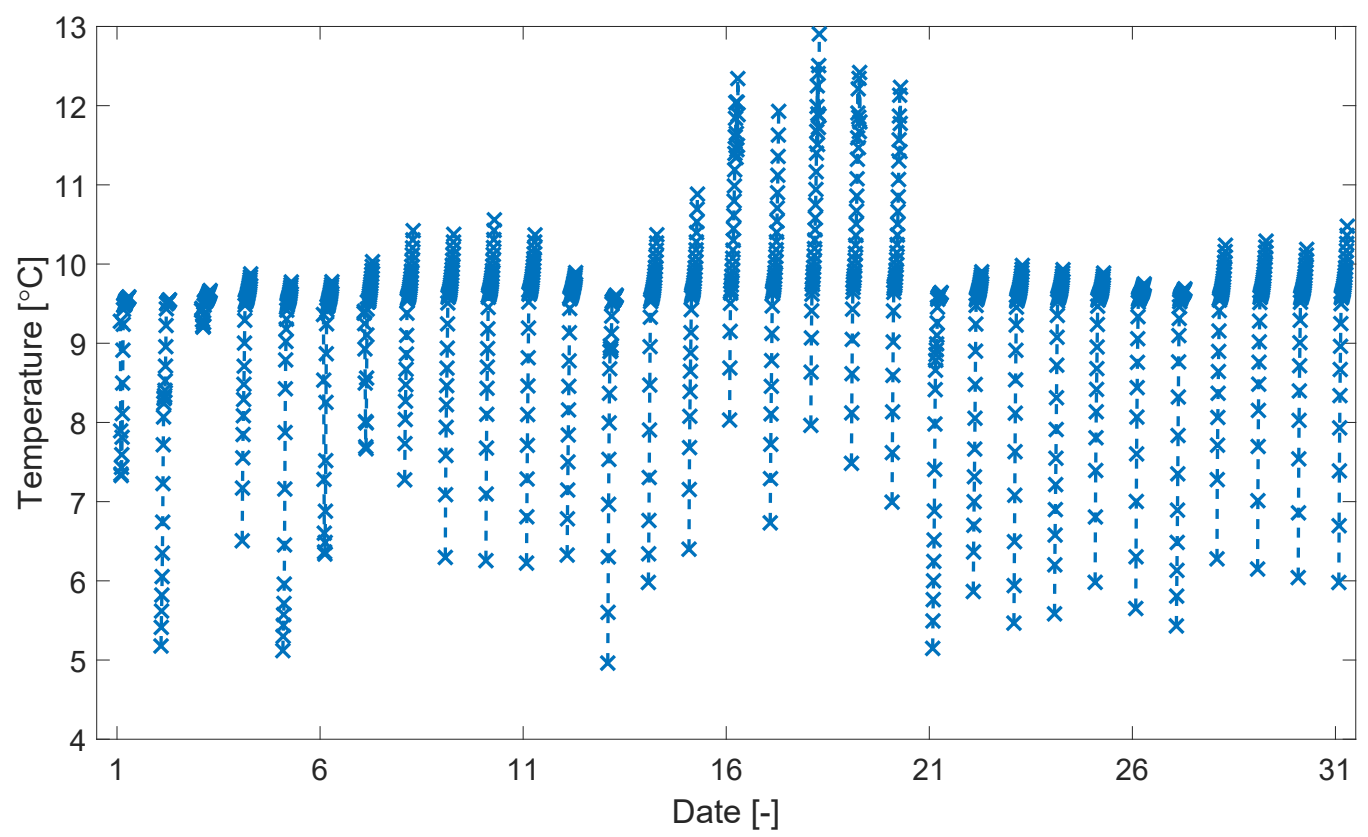

Figure 16. Inner tank outlet water temperature during the daily on-peak periods in July 


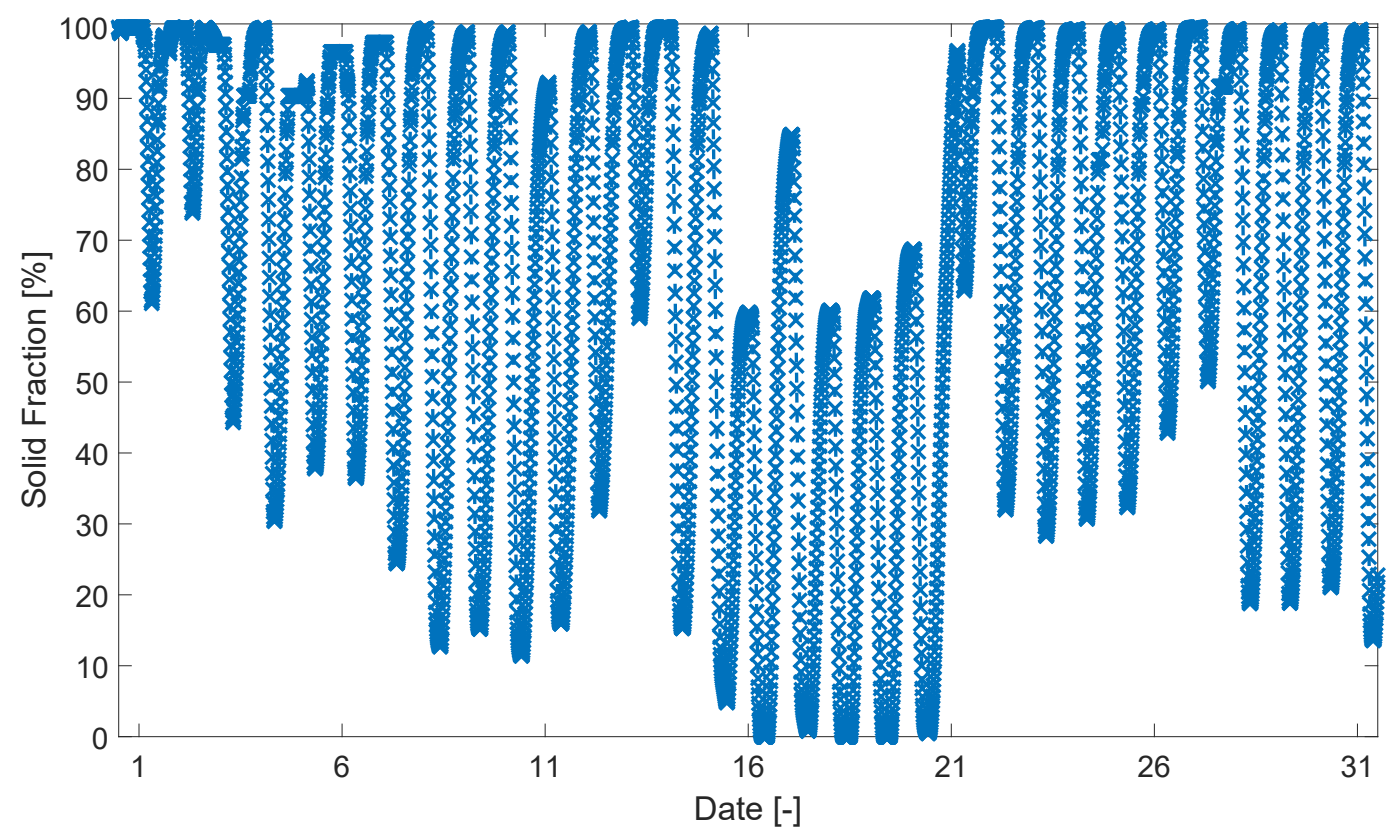

Figure 17. Solid fraction of PCMs in the inner tank in July

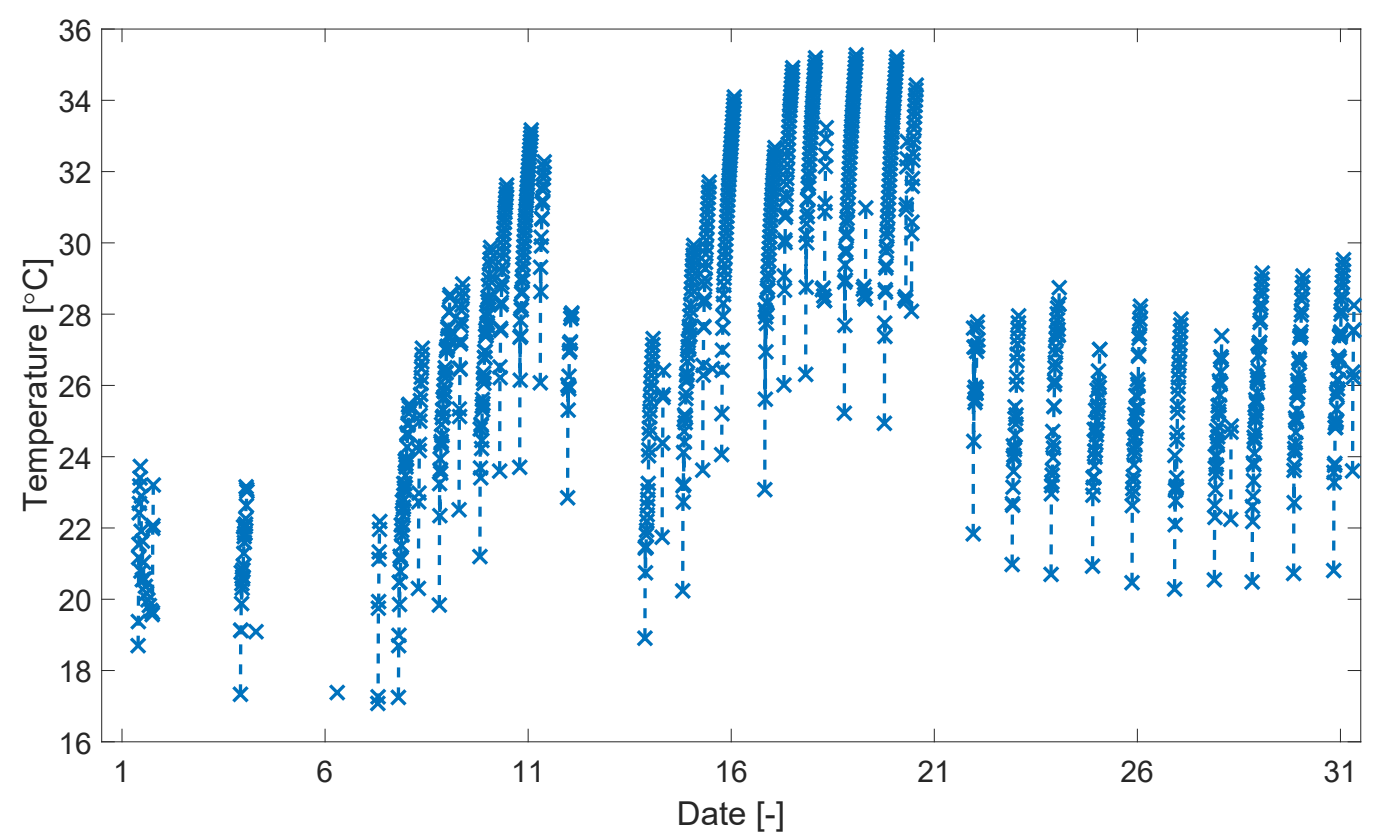

Figure 18. The outlet water temperature of the helical heat exchanger in the outer tank of the DPUTB (i.e., the source side entering water temperature of the heat pump) in July

The building power consumption and the associated cost in July are listed in Table 4. By replacing the baseline ASHP system with the DPUTB integrated DSHP system and using the rule-based control, the total power consumption of the building is increased by $15.3 \%$. This is because the thermal loss from the TES is inevitable, and the COP of the heat pump on hot days is not much better than the ASHP. To reduce electrical power consumption, a more advanced control strategy is needed. On the other hand, the on-peak power consumption is reduced by $37 \%$ when applying the proposed system and control, which results in a $15.7 \%$ reduction (\$21) in the energy cost in July based on the TOU electricity rate. 
Table 4. Building electricity consumption and associated cost in July

\begin{tabular}{lllll}
\hline System & Control & $\begin{array}{l}\text { Total electricity consumption } \\
{[\mathbf{k W h}]}\end{array}$ & $\begin{array}{l}\text { On-peak electricity consumption } \\
{[\mathbf{k W h}]}\end{array}$ & $\begin{array}{l}\text { Cost } \\
{[\mathbf{\$}]}\end{array}$ \\
\hline ASHP & conventional on/off & 1326 & 421 & 134 \\
DSHP+DPUTB & rule-based control & 1529 & 264 & 113 \\
\hline
\end{tabular}

\subsubsection{Heating Season Performance}

The inner tank can also be used to store heating energy. In cases where the required heating energy storage is larger than the required cooling energy storage, a different PCM with a high melting temperature (e.g., $40^{\circ} \mathrm{C}$ ) would be used in the inner tank for storing heat at the desired high temperature. However, in this study, the required heating energy storage is lower than the cooling energy storage due to the shorter on-peak period ( 3 hours) and the relatively mild weather in winter. Therefore the heating energy storage solely relies on the sensible heat of the water and the PCM in the inner tank. As shown in Figure 19a, the outlet water temperature of the inner tank drops from $37^{\circ} \mathrm{C}$ to $30^{\circ} \mathrm{C}$ during the 3-hour on-peak period when the sensible heat stored in the inner tank is used to meet the building's heating load. Because the soil temperature at shallow depth during cold winter days can be lower than the freezing point, propylene glycol is added to the outer tank water and the helical heat exchanger loop to prevent freezing. In the current heating season simulation, the mass concentration of the propylene glycol is $20 \%$ in the outer tank and $30 \%$ in the helical heat exchanger loop.

The operation of the DPUTB integrated DSHP system in January is simulated. Featured results for a single day (January 9) are shown in Figure 19. Similar to the cooling season results, the shaded areas represent the on-peak period of the day. Figure 19a shows that the ambient air is not used as the heat source of the heat pump for the entire day because the ambient air temperature is always below the pre-defined switching point in heating season $\left(5.0^{\circ} \mathrm{C}\right)$, therefore the DSHP runs in GSHP mode, extracting heat from the outer tank and the surrounding soil. An interesting and encouraging finding is that even though only sensible heat is stored and used for heating, the stored heat is enough to meet the heating load during the 3-hour discharging operation without running the heat pump. Figure 19a shows that the outlet water temperature from the inner tank $\left(T_{T E S, O u t}\right)$ is higher than $30{ }^{\circ} \mathrm{C}$ after discharging heat to the building for 3 hours. The outlet water temperature from the outer tank $\left(T_{G H E, O u t}\right)$ varies from 0 to $8^{\circ} \mathrm{C}$ during the day, which is higher than the ambient air temperature and enables the heat pump to run at a COP higher than 4 for the entire day. Figure 19b shows that, during the on-peak period, the electric demand of the building is dramatically reduced by replacing the baseline ASHP with the integrated DPUTB and DSHP system. The electric demand of the baseline ASHP is very high during mid-night and early morning when the electric resistance heater is turned on to supplement the ASHP for meeting the heating load. Compared with the baseline ASHP system, the integrated DPUTB and DSHP system would have reduced electricity consumption during the 3-hour on-peak period by $78 \%$ from 19.2 $\mathrm{kWh}$ to $4.3 \mathrm{kWh}$ on January 9. Besides, the EULP of the building over the whole day is also flattened by the DPUTB and DSHP system. Compared with Figure 15b, the peak electric demand on the typical winter day is very close to the peak electric demand on the typical summer day. It indicates that the integrated DPUTB and DSHP system can be used to electrify the space heating of a building without the need to increase the capacity of the existing electric supply system of the building. 


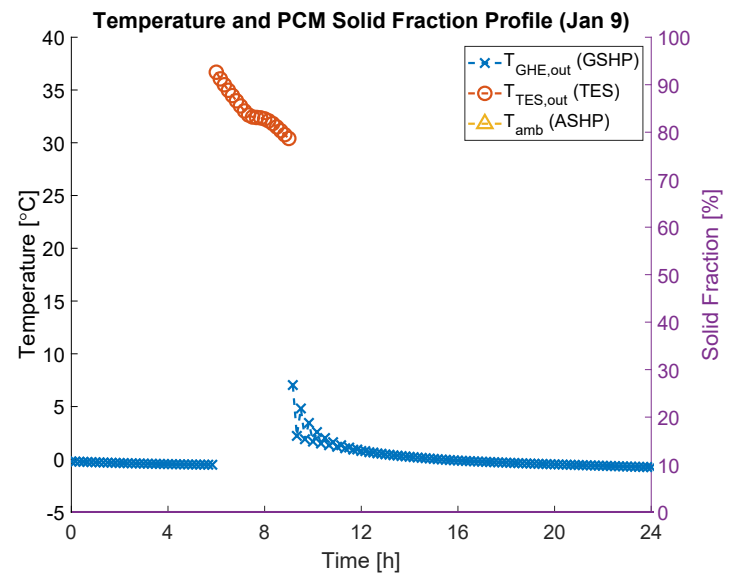

(a)

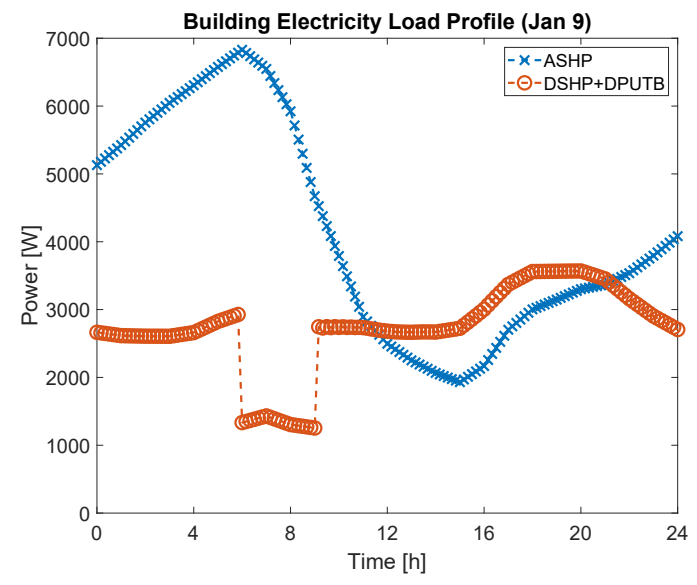

(b)

Figure 19. Featured system simulation results on January 9: (a) DPUTB and DSHP operating status; (b) building EULP resulting from the integrated DPUTB and DSHP system and the baseline ASHP system

Figure 20 shows the outlet water temperature of the inner tank during daily on-peak periods in January. It can be seen that the outlet water temperature is higher than $30^{\circ} \mathrm{C}$ while meeting all the heating loads on most days, except at the end of the on-peak period on January $21-23$, when the outlet water temperature falls between $28^{\circ} \mathrm{C}$ and $30^{\circ} \mathrm{C}$. This result implies that the sensible heat stored in the inner tank is enough for meeting all the heating loads of the simulated building during the on-peak period and the PCMs do not have to be changed in winter. Figure 21 depicts the outlet water temperature of the outer tank in January. Because of the low ambient air temperature in January, the DSHP extracts heat from the DPUTB instead of the ambient air on most days. As can be seen from Figure 21, the outlet water temperature, which is the source side entering fluid temperature of the heat pump is not lower than $-3^{\circ} \mathrm{C}$ during the entire month. It enables the heat pump to run at a COP higher than 3.5. The simulation results indicate that even though the latent heat of the PCM cannot be utilized during the heating season, sensible heat stored in the inner tank can allow shifting the 3-hour on-peak electric demand for space heating to the off-peak period without compromising the occupant thermal comfort in the building. Furthermore, the DPUTB also enables efficient heat pump operation in winter.

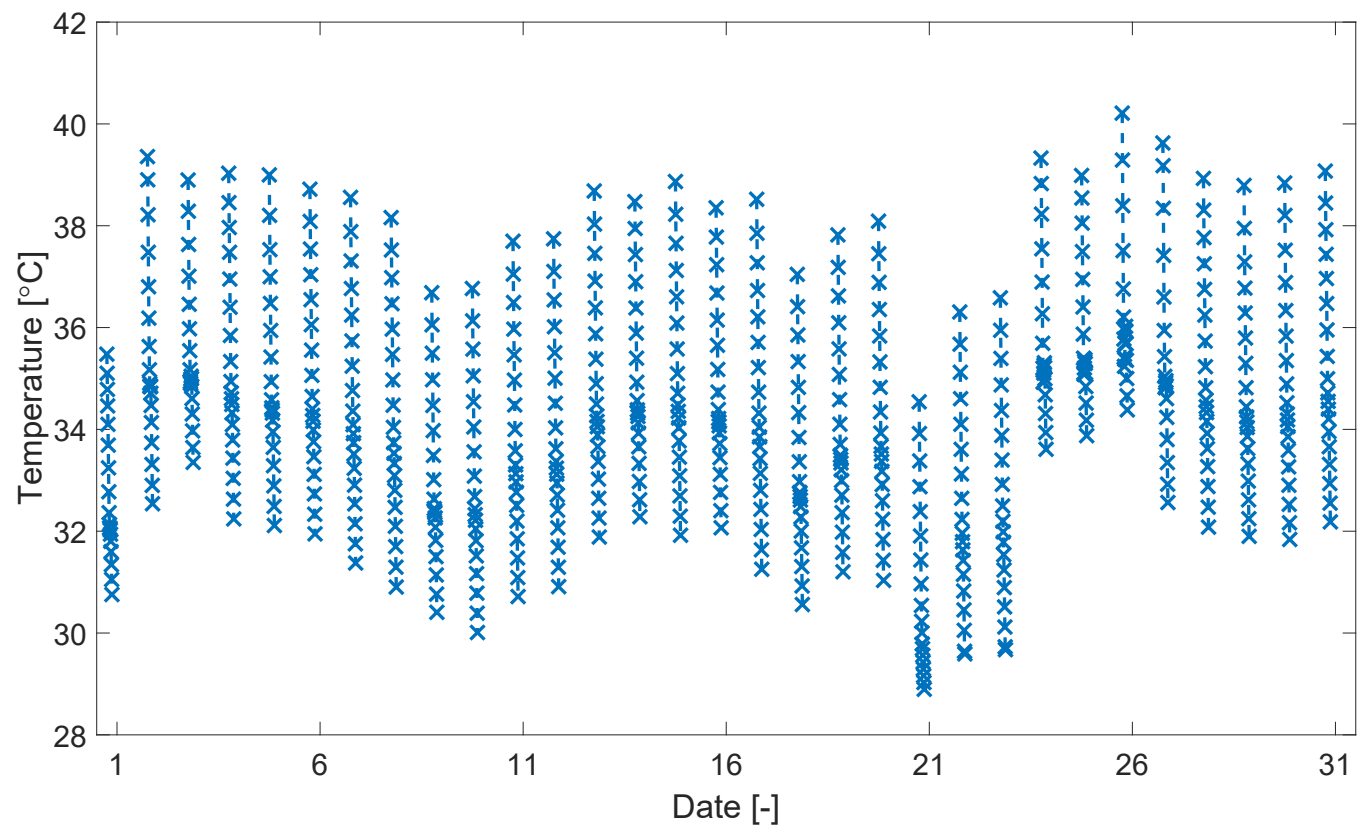

Figure 20. Inner tank outlet water temperature during the daily on-peak periods in January 


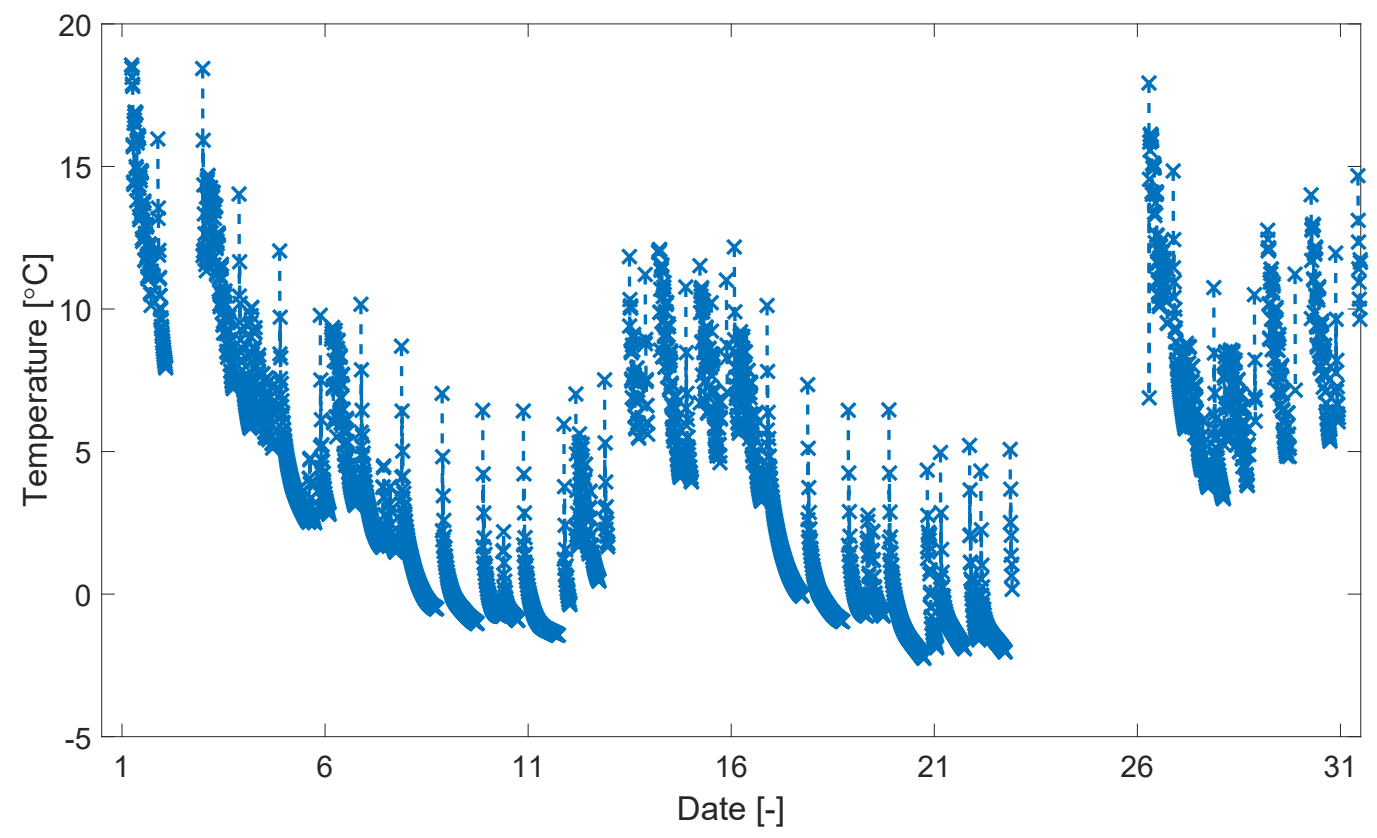

Figure 21. The outlet water temperature of the helical heat exchanger in the outer tank of the DPUTB (i.e., the source side entering water temperature of the heat pump) in January

The electricity consumption of the building and the associated cost in January are listed in Table 5. Different from the result in July (Table 4), the integrated DPUTB and DSHP system would have resulted in a $6 \%$ reduction in electricity consumption compared with the baseline ASHP system. It is because that the efficiency gain of the integrated system over the baseline ASHP system is more than offsetting the thermal loss from the inner tank to the outer tank. In January, the on-peak power consumption is reduced by $59 \%$ by replacing the baseline ASHP system with the integrated system, resulting in a $27 \%$ reduction $(\$ 42)$ in the monthly electricity bill.

Table 5. Building electricity consumption and associated cost in January

\begin{tabular}{lllll}
\hline System & Control & $\begin{array}{l}\text { Total electricity consumption } \\
{[\mathbf{k W h}]}\end{array}$ & $\begin{array}{l}\text { On-peak electricity consumption } \\
{[\mathbf{k W h}]}\end{array}$ & $\begin{array}{l}\text { Cost } \\
{[\mathbf{\$}]}\end{array}$ \\
\hline ASHP & conventional on/off & 1951 & 311 & 155 \\
DSHP+DPUTB & rule-based control & 1833 & 128 & 113 \\
\hline
\end{tabular}

The above system simulation results for summer (July) and winter (January) indicate that the current design of the DPUTB can meet the design requirement for both TES (inner tank) and GHE (the outer tank). The sensible heat in the inner tank is enough for shifting the electric demand for space heating from the on-peak period to the off-peak period, and the PCMs do not have to be changed in winter.

\section{CONCLUSIONS}

A first-of-this-kind dynamic numerical model of the DPUTB has been developed. This 2D model is capable of predicting the thermal response of the DPUTB with similar accuracy as a detailed 3D model developed using ANSYS/FLUENT (v 17.2) with 1000 times faster computational speed. The 2D model has been used to conduct a parametric study for identifying a set of design parameters of the DPUTB that can meet the targeted thermal storage performance. Furthermore, seasonal simulations of an integrated DPUTB and DSHP system for conditioning a typical single-family house in Knoxville, TN have also been performed to assess the performance of the integrated DPUTB 
and DSHP system in cooling and heating season. The following conclusions are drawn from the parametric study and the seasonal simulations:

- The inner tank shell thermal conductivity and the PCM melting temperature have significant impacts on the thermal storage performance of the DPUTB. For an $8.6 \mathrm{~mm}$ thick inner tank shell, the thermal conductivity should not be higher than $0.04 \mathrm{~W} /(\mathrm{m}-\mathrm{K})$. The PCM melting temperature should be $9.35-9.5^{\circ} \mathrm{C}$ to achieve the desired thermal storage performance given the $5^{\circ} \mathrm{C}$ charging and $14^{\circ} \mathrm{C}$ discharging water temperature. On the other hand, the inner tank diameter does not have a significant impact on thermal storage performance. A $0.45 \mathrm{~m}$ diameter inner tank is chosen because it ensures full usage of the PCM latent heat in a 4-hour discharging period.

- A DPUTB with the above-determined parameters can meet the targeted thermal storage performanceprovide 1-ton cooling for 4 hours with lower than $11^{\circ} \mathrm{C}$ cold water. The DPUTB can be fully charged (i.e., change the phase of all the PCMs in the inner tank from liquid to solid) within 8 hours using the $5^{\circ} \mathrm{C}$ charging water temperature.

- A properly sized integrated DPUTB and DSHP system for a typical single-family house in Knoxville, TN can shift electric loads for meeting the thermal demands of the building from the on-peak period to off-peak period. In July, the integrated DPUTB and DSHP system would have reduced on-peak electricity consumption by $37 \%$ compared with the baseline ASHP system. With a typical TOU electricity tariff, this load shift can result in a 16\% energy cost reduction. Even though the TES is designed and sized for storing cooling energy, its sensible energy capacity is enough for shifting electric load in the heating season. In January, on-peak electricity consumption can be reduced by $59 \%$, and the corresponding energy cost reduction is $27 \%$. 


\section{REFERENCES}

[1] EIA (2019), Electric Power Monthly with Data for August 2019. https://www.eia.gov/electricity/monthly/current month/epm.pdf.

[2] Schwartz, L. et al. (2017). Electricity end uses, energy efficiency, and distributed energy resources baseline.

[3] Lizana, J., Chacartegui, R., Barrios-Padura, A., \& Ortiz, C. (2018). Advanced low-carbon energy measures based on thermal energy storage in buildings: A review. Renewable and Sustainable Energy Reviews, 82, 3705-3749.

[4] Arteconi, A., Hewitt, N. J., \& Polonara, F. (2013). Domestic demand-side management (DSM): Role of heat pumps and thermal energy storage (TES) systems. Applied thermal engineering, 51(1-2), 155-165.

[5] Renaldi, R., Kiprakis, A., \& Friedrich, D. (2017). An optimisation framework for thermal energy storage integration in a residential heat pump heating system. Applied energy, 186, 520-529.

[6] Yan, C., Xue, X., Wang, S., \& Cui, B. (2015). A novel air-conditioning system for proactive power demand response to smart grid. Energy conversion and management, 102, 239-246.

[7] Lizana, J., Friedrich, D., Renaldi, R., \& Chacartegui, R. (2018). Energy flexible building through smart demandside management and latent heat storage. Applied energy, 230, 471-485.

[8] Hirmiz, R., Teamah, H. M., Lightstone, M. F., \& Cotton, J. S. (2019). Performance of heat pump integrated phase change material thermal storage for electric load shifting in building demand side management. Energy and Buildings, 190, 103-118.

[9] Renewable Heating and Cooling Policy Framework - NYSERDA (2020). Available online: https://www.nyserda.ny.gov/-/media/Files/Publications/PPSER/NYSERDA/RHC-Framework.pdf (accessed on 6 May 2020).

[10] Liu, X., Polsky, Y., Qian, D., Mcdonals, J. (2018). Analysis of Cost Reduction Potential of Vertical Bore Ground Heat Exchanger (Final); Oak Ridge National Lab.: Oak Ridge, TN, USA.

[11] Bertermann, D., Bernardi, A., Pockelé, L., Galgaro, A., Cultrera, M., de Carli, M., Müller, J. (2018). European project "Cheap-GSHP": installation and monitoring of newly designed helicoidal ground source heat exchanger on the German test site. Environ. Earth Sci. 77(5), 180.

[12] Cordts, D. (2011). "The GeoColumnTM Geothermal Heat Pump Company," Geothermal Energy Workshop.

[13] Najib, A., Zarrella, A., Narayanan, V., Grant, P., Harrington, C. (2019). A revised capacitance resistance model for large diameter shallow bore ground heat exchanger. Appl. Therm. Eng. 162, 114305.

[14] Zhang, M., Liu, X., Biswas, K., Warner, J. (2019). A three-dimensional numerical investigation of a novel shallow bore ground heat exchanger integrated with phase change material. Appl. Therm. Eng. 162, 114297.

[15] Warner, J., Liu, X., Shi, L., Qu, M., Zhang, M. (2020). A novel shallow bore ground heat exchanger for ground source heat pump applications-Model development and validation. Appl. Therm. Eng. 164, 114460.

[16] Anonymous. (2004). Auger Basics. National Driller Magazine. 2004 December.

[17] Fridleifsson, I. B., Bertani, R., Huenges, E., Lund, J. W., Ragnarsson, A., Rybach, L. (2008). The possible role and contribution of geothermal energy to the mitigation of climate change, Proceedings of IPCC scoping meeting on renewable energy sources, Luebeck, Germany.

[18] Bergman, T. L., Incropera, F. P., DeWitt, D. P., \& Lavine, A. S. (2011). Fundamentals of heat and mass transfer. John Wiley \& Sons.

[19] Zhao, B. C., Cheng, M. S., Liu, C., \& Dai, Z. M. (2016). Thermal performance and cost analysis of a multilayered solid-PCM thermocline thermal energy storage for CSP tower plants. Applied energy, 178, 784-799.

[20] Klein, S. A. et al. (2017). "TRNSYS 17: A Transient System Simulation Program.” Solar Energy Laboratory, University of Wisconsin, Madison. http://sel.me.wisc.edu/trnsys.

[21] Prabhanjan, D. G., Rennie, T. J., \& Raghavan, G. V. (2004). Natural convection heat transfer from helical coiled tubes. International Journal of Thermal Sciences, 43(4), 359-365.

[22] Xing, L.; Spitler, J. D. (2017). Prediction of undisturbed ground temperature using analytical and numerical modeling. Part I: Model development and experimental validation. Sci. Technol. Built. En. 23(5), 787-808.

[23] Lemmon, E. W., McLinden, M. O., and Friend D. G. (2020). "Thermophysical Properties of Fluid Systems," in NIST Chemistry WebBook, NIST Standard Reference Database Number 69, Retrieved., Linstrom, P. J., and Mallard, W. G., Eds. Gaithersburg, MD: National Institute of Standards and Technology. 
[24] Baltimore Gas and Electricity Company. (2018). Residential delivery and energy time-of-use pilot - electric schedule RD. https://www.bge.com/MyAccount/MyBillUsage/Documents/Electric/Schedule_RD.pdf

[25] Southern California Edison. (2020). Time-Of-Use Residential Rate Plans. https://www.sce.com/residential/rates/Time-Of-Use-Residential-Rate-Plans

[26] Citizens Utility Board of Minnesota. (2020). Time-of-Use Rates. http://cubminnesota.org/library/time-of-userates/

[27] DOE, Residential Prototype Building Models.

https://www.energycodes.gov/development/residential/iecc models

[28] Wilcox, S. and W. Marion. (2008). User's Manual for TMY3 Data Sets, NREL/TP-581-43156. April 2008. Golden, Colorado: National Renewable Energy Laboratory.

[29] Eli A. Goldstein, Aswath P. Raman, and Shanhui Fan, 2017, Sub-ambient non-evaporator fluid cooling with the sky, Nature Energy, Vol. 2, \#17143 